\title{
Too Big to Ignore? Hedge Fund Flows and Bond Yields*
}

\author{
Olga Kolokolova, Ming-Tsung Lin, Ser-Huang Poon ${ }^{\dagger}$
}

December 21, 2017

\begin{abstract}
This paper investigates the information content of aggregate hedge fund flow and its predictive power with respect to bond yields. Using a sample of 9,725 hedge funds from 1994 to 2012, we find that fund flow is negatively related to the changes in 10-year Treasury and Moody's Baa bond yields one month ahead. The relation is still pronounced after controlling for other determinants of yield changes, including the amount of arbitrage capital available in the economy, suggesting a non-trivial effect of flow-induced hedge fund trading on bond yields. Flow impact on corporate bonds is further amplified during periods of decreasing market liquidity, consistent with a fire-sale hypothesis. Hedge fund flow also predicts convergence between constant maturity swap rate and constant maturity Treasury rate, as well as between the TIPS and Treasury bond yields, suggesting that hedge funds exploit arbitrage opportunities in these fixed-income markets.
\end{abstract}

Key words: Hedge funds; flows; bond yields

JEL classification: G12; G23

${ }^{*}$ We thank Michael Brennan, Robert Kosowski, Alex Kostakis, Marcin Michalski, the participants of the IFABS 2016 Barcelona conference, and two anonymous referees for helpful comments. All errors remain ours.

†Olga Kolokolova (olga.kolokolova@manchester.ac.uk), and Ser-Huang Poon (serhuang.poon@manchester.ac.uk) are at the University of Manchester, Alliance Manchester Business School, Ming-Tsung Lin (ming-tsung.lin@dmu.ac.uk) is at the De Montfort University, Department of Accounting and Finance. 


\section{Introduction}

Hedge funds are active investment managers, which are only loosely regulated. They can take leverage, short sell, and implement various dynamic trading strategies with frequent portfolio re-balancing. The total size of the industry exceeded USD $\$ 3$ trillion as of the end of the first quarter of 2017. The capital concentration in the largest funds makes it possible for them to move prices of the assets they trade away from the fundamental values by affecting the demand for these assets. Using long equity positions of hedge funds, as reported in the $13 \mathrm{~F}$ filings to the Security and Exchange Commission (SEC), Ben-David et al. (2013) show that hedge fund trading is likely to be a cause of abnormal price moves around quarter ends of stocks they hold. The bond market (especially for corporate bonds) is less liquid than the equity market. Given the large trading volume attributed to hedge funds in these market: $2^{2}$ and the importance of the fixed income markets for other investors (e.g., pension funds), the question of the potential impact on bond prices by hedge fund trading is of great importance.

Previous research, however, has mostly focused on hedge fund links to equity markets. The research on the effects of hedge fund trading on bond markets is rather scarce, and the links between hedge fund trading and bond markets are often only investigated indirectly. Choi et al. (2010) focus on the convertible bond market, and find that the flow of convertible bond arbitrage hedge funds explains the number of convertible bonds issued. Kruttli et al. (2015) show that the aggregate liquidity of hedge funds predicts future returns on bonds, among other assets. Fleckenstein et al. (2014) suggest that the amount of arbitrage capital measured by flows into the hedge fund industry leads to decreasing profitability of a trading strategy that exploits Treasury Inflation Protected Securities (TIPS)-Treasury bond relative mispricing.

Our paper further extends this body of literature and examines the impact of flow-induced hedge fund trading on the fixed income market and the resulting predictability of bond yields. We consider a relatively illiquid corporate bond market and a highly liquid Treasury bond market, and proxy their performance by monthly changes in Moody's Baa corporate bond yield and monthly changes in the 10-year Treasury bond yield. Despite the differences in their

\footnotetext{
${ }^{1}$ According to Hedge Fund Research, Inc., https://ww. hedgefundresearch.com/index.php?fuse= products-irglo.

${ }^{2}$ E.g., hedge funds purchase up to $75 \%$ of the convertible bonds (Choi et al. 2010), and account for $20 \%$ of the trading volume in the U.S. Treasury bond market (Financial Times, August 11, 2010).
} 
liquidity, both types of bonds are relatively risky within their respective asset classes and are likely to be held long by hedge funds.

At the same time, hedge funds often engage in long-short strategies. Thus, their trading may have opposite effects on prices of the long and short legs of such strategies. We consider three widely used bond arbitrage trading strategies, the profitability of which depends on the spreads between various pairs of fixed income securities. In particular, we consider changes in yield spread between on-the-run and off-the run bonds (Krishnamurthy, 2002), constant maturity swap rate and constant maturity treasury rate (Duarte et al., 2007), and TIPS and Treasury bonds (Fleckenstein et al., 2014).

In contrast to previous research focusing on percentage fund flow, in this study we use dollar flow, which can better capture the magnitude of hedge fund trading and external liquidity shocks. We scale dollar fund flow by the U.S. GDP as of the end of the previous year to control for the exponential growth of the industry with respect to the size of the economy and the rate of inflation.

Our paper contributes to the discussion on the potential impact of hedge funds on financial markets. It provides strong empirical evidence on the predictability of changes in bond yields by hedge fund flows, pointing towards a non-negligible effect of flow-induced hedge fund trading on prices of fixed income securities. We make several contributions to the literature. First, we find that dollar flow to hedge funds is negatively related to changes in yields of 10-year Treasury bonds and Baa-rated bonds one month ahead. Second, our results point to differences in the economic mechanism of the link between fund flows and Treasury and corporate bond yield changes. The effect on Treasury bonds is driven by inflow, suggesting that hedge funds may (temporarily) allocate excess cash to safe government securities, pushing their prices upwards. But it is both outflow and inflow that contribute to predictability of corporate bond yield changes, suggesting a direct price effect of flow-induced trading. The impact on corporate bonds is further amplified during periods of decreasing market liquidity, which is consistent with the fire-sale hypothesis and liquidity spiral proposed by Brunnermeier and Pedersen (2009). Next, we show that this predictability is largely associated with inflow and outflows of the largest $25 \%$ of hedge funds. The predictive power increases over time with the growth of the hedge fund industry. The strongest impact in recent years is linked to outflows from large bond-trend 
following hedge funds. Last but not least, fund flow predicts convergence in constant maturity treasury bond yield and swap rate, making the Treasure-swap spread arbitrage trading strategy less profitable. A similar effect is found for TIPS-Treasury spread for 30-year bonds. These findings indicate that hedge funds exploit arbitrage opportunities on fixed income markets, and reduce mispricing.

\section{Related Literature}

This paper is related to a vast literature discussing potential links between hedge fund activity and financial market performance. In particular, Kruttli et al. (2015) show that the aggregate liquidity of hedge funds, proxied by the average hedge fund return serial correlation coefficient, has predictive power for future returns on stock, bond, and currency indices. Kang et al. (2014) link hedge fund trading and stock-idiosyncratic volatility. Choi et al. (2010) investigate convertible bond issuance and convertible bond arbitrage hedge funds. These arbitrageurs are primary purchasers on that market and the inflow to funds is a funding resource for the purchase. The authors find that the flow of convertible bond arbitrage hedge funds explains the number of the convertible bonds issued.

Although the data on detailed hedge fund holdings are not available, previous research has analysed the impact of reported equity holdings of large hedge fund investment companies on equity markets using 13F filings submitted to the SEC. Ben-David et al. (2012) find that the changes in stock holdings are mainly driven by hedge fund flow. Given the substantial sell-off in hedge fund equity holdings during the financial crisis of 2007-2008, clients' redemption is likely to be the main reason for hedge funds' stock selling. The authors claim that (institutional) clients of hedge funds fear fund managers may lock up the money if funds perform poorly. Therefore, these clients tend to be very sensitive to market turbulence and, as a result, money withdrawal becomes more severe than in other investment vehicles such as mutual funds. In addition, Ben-David et al. (2012) suggest that hedge funds reallocate their capital from stocks to sovereign and corporate bonds, as the correlations of hedge fund return and the corresponding asset indices increased during the financial crisis.

Jiao (2013) investigates hedge fund holdings reported in the $13 \mathrm{~F}$ forms between 2000 and 
2009 and finds that they are positively related to equity returns one quarter ahead, prior to 2007. Jylha et al. (2014) show that hedge funds provide liquidity to the stock market, often acting as contrarian traders. Cella et al. (2013) study the trading behaviour of the $13 \mathrm{~F}$ institutional investors, including mutual funds and hedge funds. They find that institutional investors with short trading horizons react more strongly to market shocks than investors with long trading horizons. Upon realization of the market shock, short-horizon investors sell large amounts of their stock holdings, and the resulting fire sales create price pressure in the stock market. The fire sales also affect the prices of other assets held by the same institutional investors (Coval and Stafford, 2007).

Chan et al. (2005) show that returns on the S\&P 500 index, a synthetic bank index, a bond index, and several other indices are related to hedge funds performance. Boyson et al. (2010) apply the Co-movement Box proposed by Cappiello et al. (2014) and find contagion between hedge fund returns and market returns in small-cap, mid-cap, and emerging market equities, as well as high-yield and emerging market bonds. Dudley and Nimalendran (2011) find asymmetric correlation between hedge fund returns and returns on the equity index. Funds with low returns are more likely to co-move with the equity market, indicating the possibility of contagion risk among funds that face funding constraints.

Liquidity risk is also important in determining hedge fund performance and its market impact. Sadka (2010) finds that systematic liquidity risk, measured by the Sadka illiquidity measure, has a strong explanatory power for hedge fund returns. Teo (2011) reports significant illiquidity risk premia; funds that are highly exposed to liquidity risk outperform those with low liquidity risk exposure. Hu et al. (2013) use a liquidity measure based on the noise of Treasury bond yields to capture the shortage of arbitrage capital in the economy. They show that this illiquidity measure explains hedge fund returns in addition to traditional factors that are not related to liquidity.

In the aftermath of the subprime mortgage crisis, the UK Financial Services Authority (FSA), a body responsible for regulating financial industry in the UK between 2001 and $2013^{3}$. commissioned a series of reports in 2009-2010 to assess the systemic risk posed by hedge funds.

\footnotetext{
${ }^{3}$ The FSA was dissolved on the 1st of April 2013. It is replaced by two authority bodies, namely, the Financial Conduct Authority (FCA) and the Prudential Regulation Authority (PRA).
} 
The FSA investigation focuses only on defaults of hedge funds and the resulting counterparty risks that systemically important financial institutions (SIFIs) are exposed to. The FSA reports conclude that hedge funds do not pose any systemic risk to the financial system and the wider economy. This conclusion, however, may underestimate the influence of hedge funds, as it neglects possible contagion effects and price impact of large hedge funds. In particular, as of 2012, the largest $1 \%$ of hedge funds controlled $38 \%$ of the assets in the hedge fund industry, with $90 \%$ of the assets being controlled by only the top $25 \%$ of funds according to the large merged hedge fund database used in this paper. Large hedge funds are particularly important as they are the alternative investment outlets for institutional investors (Joenvaara et al., 2014), and they are becoming more interwoven with other large financial institutions (Billio et al., 2012).

\section{$3 \quad$ Research Design and Hypotheses}

\subsection{Flow-induced price pressure}

In this paper, we attempt to capture the link between hedge fund trading and changes in corporate bond yields (measured by the Moody's Baa yield) and changes in government bond yields (measured by the 10-year Treasury bond yield). Since these assets are relatively risky within their respective asset classes (Baa bonds are riskier than Aaa bonds, and 10-year Treasury bonds are riskier than short-term bonds) hedge funds are likely to hold long positions in these bonds..$^{4}$ An increase in demand for these assets from hedge funds should lead to a decline in their prices and, consequently, an increase in yields. Hedge fund bond portfolio holdings, unfortunately, are not publicly available $5^{5}$ and direct inference is not possible.

We recognize, however, that upon fund inflow and outflow, hedge funds are more likely to

\footnotetext{
${ }^{4}$ Baa bonds have higher default risk than Aaa bonds. The corresponding average one-year default probabilities are $0.29 \%$ and $0.00 \%$ respectively, according to Moody's https://www.moodys.com/sites/products/ DefaultResearch/2007400000578875.pdf. Consequently, the average yield of Baa bonds in our sample of $7.11 \%$ per month is higher than that of Aaa bonds (6.13\%). Similarly, 10-year Treasury bonds have longer duration and higher interest rate risk than short-term bonds and notes. To compensate for this, 10-year Treasury bonds yield on average $4.70 \%$ per year, whereas 3 -month Treasury bills yield $3.05 \%$ for our sample periods according to H.15 Release.

${ }^{5}$ Large hedge fund investment companies are required to disclose parts of their equity holdings (long positions in U.S. equities and some option holdings) through SEC 13F filings. The information is available only for a small number of hedge funds. The $13 \mathrm{~F}$ reports are completed quarterly. The assets included in these filings cover largely U.S. equity and do not include bond holdings. Thus, the $13 \mathrm{~F}$ information is not suitable for the current analysis.
} 
trade, especially when they encounter large withdrawal amounts from investors Ben-David et al., 2012). Flow-induced trading of mutual funds, for example, is examined in Coval and Stafford (2007). The authors show that mutual funds respond to inflow (outflow) by increasing (decreasing) the existing equity positions, creating additional price pressure. If hedge funds behave alike, facing clients' redemptions, fund managers may have to sell parts of their portfolios, depressing market prices (and bond prices, in the context of our study) in the meantime. A lower bond price is translated into a higher bond yield. The reverse effect may be observed upon fund inflows. This leads to our first hypothesis on flow-induced price pressure in bond markets.

H1: Hedge fund flow is negatively related to future changes in bond yields.

To test this hypothesis, we regress changes in bond yields on changes in the lagged fund flow.

What distinguishes this paper from previous research on fund flow is the usage of dollar flow instead of conventionally used percentage flow. Percentage fund flow can adequately capture neither the magnitude of trading activity nor the severity of market liquidity shocks. Consider a simple example: compare two funds with $\$ 10$ million assets under management (AuM) and $\$ 1$ million AuM respectively. Both funds experience outflows and need to sell 10\% of their bond positions immediately. The large fund will sell $\$ 1$ million worth of bonds, whereas the small one will sell only $\$ 0.1$ million worth of bonds. The large fund is more likely to cause a price impact by selling ten times more bonds than the small fund, despite the same percentage outflow. Similarly, when aggregating the flow information across all hedge funds we chose to use the sum of the individual dollar flows and not the average dollar flow to capture the magnitude of fund inflow and outflows to/from the hedge fund industry.

DollarFlow ${ }_{i, t}$ denotes the monthly net dollar flow at time $t$ to individual hedge fund $i$ :

$$
\operatorname{DollarFlow}_{i, t}=A u M_{i, t}-\left(1+R_{i, t}\right) \times A u M_{i, t-1}
$$

where $R_{i, t}$ is the reported return of hedge fund $i$ at time $t$, and $A u M_{i, t}$ represents the corresponding assets under management. We then sum up all individual flows and scale the sum 
by the U.S. GDP as at the end of the previous year to obtain the aggregate dollar flow in the hedge fund industry, Dollar Flow . The scaling allows us to better capture the size of fund flow relative to the economy and to control for inflation over the sample period. $!^{6}$

The challenge in identifying the impact of hedge fund trading using flow as a proxy is that hedge fund flow contains different types of information. First, it proxies for hedge fund trading activity, as upon inflow and outflow hedge funds are likely to rebalance their portfolios. At the same time, fund flow captures the overall market conditions, funding liquidity, and the amount of capital available for risky investments. Withdrawals may also be related to investors' background risk, such as meeting personal liabilities.

To disentangle the trading impact of hedge funds from other types of information captured by fund flow we use as a control variable the change in the "noise" measure of Hu et al. (2013). This measure is based on the deviations of the observed prices of U.S. Treasury bonds from their fitted values. It proxies for market-wide liquidity and captures the amount of the arbitrage capital in the market. If flow-induced trading of hedge funds does not have any material impact on bond yields, and fund flow simply reflects other investors' liquidity needs, our Dollar Flowt measure should be insignificant in the presence of the noise measure.

We also use several additional control variables, including the average excess returns and average percentage flows of bond-oriented mutual funds (as mutual funds actively participate in bond markets), the CBOE VIX index and lagged bond yields as macroeconomic variables, following Choi et al. (2010). We control for the effect of the financial crisis of 2007-2009 by introducing a corresponding crisis dummy.7

\footnotetext{
${ }^{6}$ As a robustness check, in Section 6 we use two different types of scaling, namely, by the total size of corporate bonds issues and by the size of Treasury bond issues during the year, and obtained qualitatively similar results.

${ }^{7}$ As a robustness check we use dollar mutual fund flow scaled by the GDP instead of the percentage flow to make them comparable to our flow specification for hedge funds. We also include a change in the Baa-Aaa yield spread and a change in slope of the yield curve (the spread between 10-year Treasury bond and 3-month treasury bill yields) as additional controls. The results remain qualitatively the same, and are discussed in Section 6 .
} 
Our baseline regression is as follows:

$$
\begin{aligned}
\Delta \text { Yield }_{t} & =\beta_{0}+\beta_{1} D_{\text {Crisis }}+\beta_{2} \Delta \text { Yield }_{t-1} \\
& +\beta_{3} \Delta \text { VIX } X_{t}+\beta_{4} \Delta \text { Noise }_{t} \\
& +\beta_{5} \text { MFExRet }_{t-1}+\beta_{6} \text { MFFlow }_{t-1}+\beta_{7} \text { HFExRet }_{t-1} \\
& +\gamma \Delta \text { DollarFlow }_{t-1}+\varepsilon_{t}
\end{aligned}
$$

where Yield is the Moody's Baa yield or U.S. 10-year Treasury bond yield. $D_{\text {Crisis }}$ is a dummy variable capturing the financial crisis. It takes a value of one between July 2007 and February 2009. VIX is the level of the CBOE VIX index. Noise is the noise measure of $\mathrm{Hu}$ et al. (2013). Following Choi et al. (2010) and $\mathrm{Hu}$ et al. (2013), we use contemporaneous changes in VIX and Noise to control for the amount of arbitrage capital available in the economy during the evaluation period. MFExRet is the average excess return of bond-oriented mutual funds over the risk-free rate. MFFlow is the average percentage flow to bond-oriented mutual funds. HFExRet is the average excess return of hedge funds over the risk-free rate. 8 Dollar Flow is the aggregate hedge fund dollar flow. The flow to the hedge fund industry has been steadily increasing over the sample period, resulting in Dollar Flow being a trending variable. To ensure reliable inference, we use changes in DollarFlow in the regression. In order to achieve a reliable inference on statistical significance of the results, we estimate Newey-West heteroskedasticity and serial correlation adjusted standard errors throughout all the regression specifications.

\subsection{Fire sale (purchases) by hedge funds in illiquid markets}

Ben-David et al. (2012) claim that (institutional) clients of hedge funds tend to withdraw their money quickly when the market becomes turbulent, for fear that fund managers may impose redemption restrictions ("raise the gates") whenever they suffer heavy losses. Such redemptions force hedge funds to liquidate their assets, and are likely to contribute to a liquidity spiral (Brunnermeier and Pedersen, 2009), especially if market liquidity is already low. If hedge funds face losses due to declining markets, and clients' redemption force them to sell

\footnotetext{
${ }^{8}$ We use the 10-year U.S. Treasury bond yield obtained from the H.15 Release as the risk-free rate, http://www.federalreserve.gov/releases/h15/data.htm
} 
their holdings quickly, this further depresses market prices, leading to further losses and fund outflows. Other financial institutions, such as pension funds that have stop-loss provisions in their risk management systems, might join the run, spreading the fear of possible massive losses and causing a liquidity drain-out $9^{9}$ We expect the impact of fund flow on bond yields to be more pronounced during turbulent market conditions when market liquidity is low.

H2: The negative relation between fund flow and bond yields is stronger at times of declining market liquidity.

In order to test this hypothesis, we re-estimate Equation (2) including an interaction term between changes in dollar fund flow and changes in the noise measure $(\Delta$ Noise $\cdot \Delta$ Dollar Flow). We expect the loading on this interaction to be negative and significant, especially for less liquid corporate bonds.

\subsection{Asymmetric effect on inflow and outflow}

Fund flow, however, does not map one-to-one in the corresponding value of the assets immediately purchased or sold. The pressure on hedge funds to trade is expected to be higher upon an outflow than upon an inflow. Upon an inflow, hedge fund managers are not required to immediately purchase any assets, whereas in case of a sudden outflow they might need to rapidly liquidate parts of their portfolios to meet redemption demand. Furthermore, outflow can lead to a deleveraging of hedge funds, and the actual quantity of assets sold in this case will be even higher than that implied by the net outflow. This is likely to happen during turbulent, low liquidity periods in markets. ${ }^{10}$ At the same time, inflows are unlikely to lead to immediate change in leverage. Hence, we expect fund outflow and inflow to have asymmetric impacts on bond yields.

\footnotetext{
${ }^{9}$ Khandani and Lo (2007) and Khandani and Lo (2011) report that during the week of August 6, 2007, when some multi-strategy funds and proprietary trading desks started to liquidate their equity portfolios to stop further losses, such sudden liquidations had a profound impact on price levels, resulting in margin calls to long-short equity hedge funds. This was then followed by pension funds' decisions to withdraw their investments from hedge funds, which put further pressure on the hedge fund industry and the financial markets. The chain of events finally resulted in unprecedented losses of several high-profile quantitative long-short equity hedge funds and substantial market price movements.

10 Ang et al. (2011), for example, show that hedge fund leverage is time varying. It was declining from mid-2007 and reached its lowest value in early 2009.
} 
H3: Inflow and outflow of hedge funds have different predictive power for bond yields during times of high and low market liquidity.

In order to test this hypothesis, we split the aggregate dollar flow into inflow and outflow:

$$
\begin{aligned}
\text { DollarInflow } & =\sum_{i} \text { DollarFlow }_{i, t} \cdot I_{\text {DollarFlow }_{i, t}>0} \\
\text { DollarOutflow }_{t}^{O} & =-\sum_{i} \text { DollarFlow }_{i, t} \cdot I_{\text {DollarFlow }_{i, t}<0}
\end{aligned}
$$

We include inflow and outflow separately in Equation (2) together with the product of a chosen flow measure and $\Delta$ Noise. We change the sign of negative flows (outflows) to positive for the ease of interpretation. We expect the loading on Dollar Inflow to be negative and the loading on DollarOutflow to be positive.

\subsection{Flow to the largest funds}

Hedge funds are not uniformly distributed with respect to their size. The total assets under management (AuM) of four hedge fund portfolios sorted by fund size one month before is depicted in Figure 1. There is a substantial difference between the total AuM for all funds and the total excluding the top $25 \%$. This gap shows that a small group of the largest funds controls the bulk of the assets in the hedge fund industry. Such high capital concentration suggests that analysing a complete sample of hedge funds in relation to price impact, implicitly putting equal weights on performance of all funds, may be misleading as it dilutes the impact of the top funds that control $90 \%$ of the total assets. Further, the top $25 \%$ of funds are likely to attract institutional investors, and their flows are expected to be larger in magnitude. Indeed, these largest funds attract more than $83 \%$ of all monthly flows into the hedge fund industry. The flows to top $25 \%$ and bottom $75 \%$ of funds are highly correlated with a correlation coefficient of 0.79. At the same time, top funds attract on average 10 times larger flows than bottom funds put together. Hence, the top $25 \%$ of funds is a good representative of the hedge fund sector.

H4: Flow of the top 25\% of funds is a stronger bond yield predictor than that of other funds. 
Figure 1: Total AuM of the AuM-Sorted Portfolios

The figure plots the total AuM for four AuM-sorted portfolios from 1994 to 2012. The solid line is the sum of the total AuM across all four portfolios. The dashed line is the total AuM of all portfolios excluding the top $25 \%$ of funds. The dashed and dotted curve represents $\mathrm{AuM}$ in the bottom two quartile portfolios, and the dotted curve is the AuM of the portfolio containing the smallest $25 \%$ of funds.

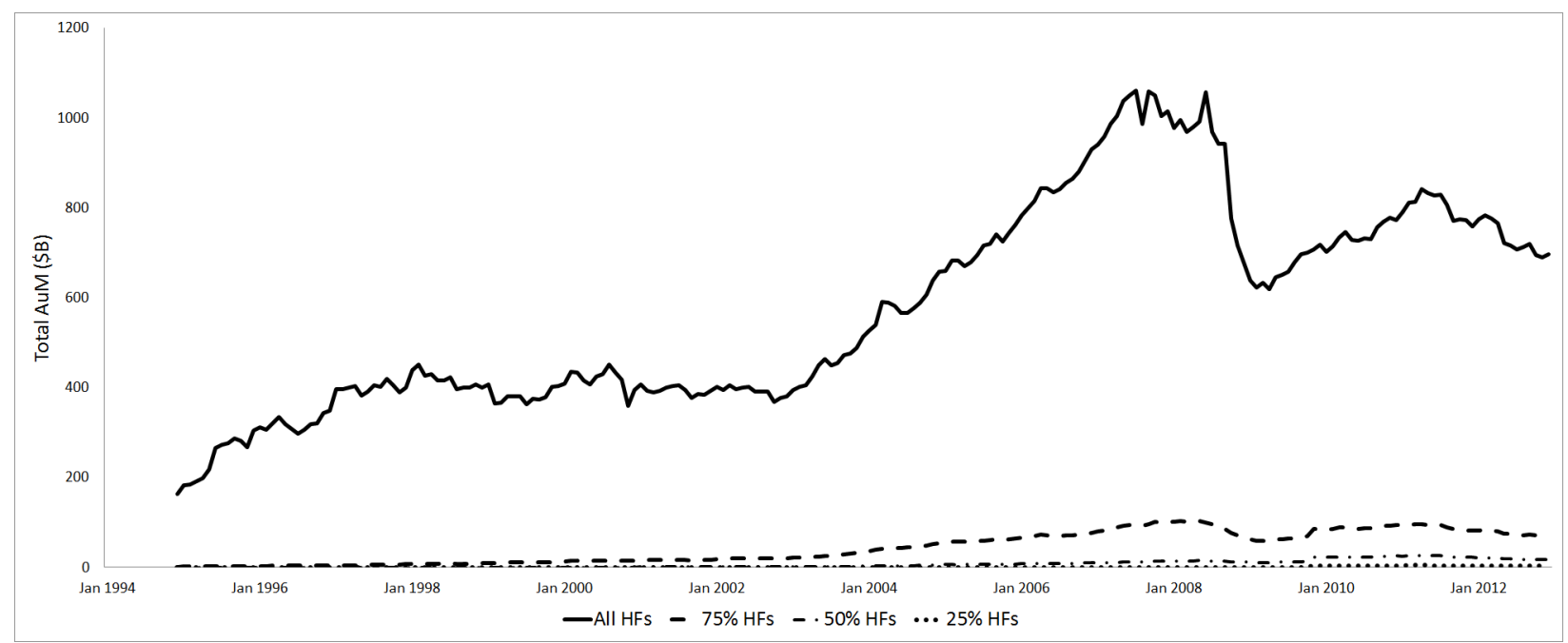

To test this hypothesis, we further split flows into those generated by the largest $25 \%$ of funds ("Top" funds) and the remaining funds ("Bottom" funds). We then repeat the complete analysis described in previous sections using flow to Top and Bottom funds in turn.

\subsection{Flow to bond-trend following hedge funds}

Naturally, not all hedge funds engage in bond trading. By isolating those funds that do hold bonds in their portfolio, one should be able to better gauge the price impact of their trading activity on the bond market. Since bond holdings are not reported by even the largest hedgefund investment companies and reported fund styles may not be accurate, we resort to an indirect inference of hedge fund investment style. For each hedge fund, we estimate a Fung and Hsieh (2004) seven-factor model ${ }^{11}$ We consider those funds with the loading on the bond-trend following factor above the median to be bond-trend following funds and repeat the analysis using flow to only this group of funds to test the following corollary:

Corollary: Flow to bond-trend following funds is a stronger predictor of future yield changes than flow to other funds.

\footnotetext{
${ }^{11}$ The time series of the factors are generously provided by David A. Hsieh in his data library https://faculty.fuqua.duke.edu/ dah7/HFData.htm.
} 


\subsection{Yield convergence in fixed-income arbitrage strategies}

So far, we have discussed the potential impact of hedge fund trading on yields of bonds, which are likely to be held long by hedge funds. Many hedge funds, however, are allowed to implement long-short strategies. If they do so using various yield-arbitrage strategies, their flows will induce changes in position in both long and short legs of the trade, affecting the spread. For such a strategy, one would expect a negative relation between fund flow and the yield spread, which drives strategy profitability. Upon an inflow, hedge funds purchase more of fixed income assets on the long leg of a trade, pushing their prices up and yields down, while selling more assets on the short leg of the trade has a reverse effect on prices and yield of the underlying bonds. Combined together, the yields converge and the profitability of the strategy declines, which leads to our final hypothesis:

H5: Flow to hedge funds is negatively related to future changes in the yield spreads underlying fixed-income arbitrage trading strategies.

To test this hypothesis, we consider three often discussed trading strategies, in which hedge funds can be potentially involved. These strategies are based on the relative mismatch of (1) on-the-run and off-the-run treasury bond yields (Krishnamurthy, 2002); (2) constant maturity swap rate and constant maturity treasury rate (Duarte et al., 2007); and (3) yields on TIPS and treasury bonds (Fleckenstein et al., 2014).

For each of these strategies we define a yield spread $S$. The spread is the difference in yields underlying the long and short legs of the trade, and it is the key driver of the profitability of the corresponding strategy. We then relate the changes in the spread to the changes in fund flow as in Equation 2. We also include additional strategy-related control variables. In what follows, we detail the spread construction process for each of the trading strategies.

(1) On-the-run and off-the-run bond arbitrage

This trading strategy exploits the relative mispricing of on-the-run and off-the-run 30-year Treasury bonds, as discussed in Krishnamurthy (2002). An arbitrageur short sells a new bond upon its issuance at a spread of about 12 basis points (bps) to the "old", off-the-run bond and simultaneously purchases the old bond in order to bet on the spread. The position is held 
until the next auction date (usually in six months), and then it is unwound at a smaller spread (potentially as small as 3 bps). The key driver of the strategy's profitability is the spread in yields between on-the-run and off-the-run bonds on the date of an auction and its decline over time. We compute the spread $S$ using 30-year Treasury bonds as

$$
S=\text { yield }_{\text {off-the-run }}-\text { yield }_{\text {on-the-run }}
$$

(2) Swap spread arbitrage

We follow Duarte et al. (2007) in constructing this arbitrage strategy. An arbitrageur enters into a par swap. They will receive a fixed coupon rate CMS (constant maturity swap rate) and pay a floating rate (Libor). Simultaneously, they short a par Treasury bond with the same maturity as the swap and invest the proceeds in a margin account earning the repo rate. On the short bond position the arbitrageur pays the constant maturity treasury rate (CMT). Taken together, the arbitrages receives the difference between CMS and CMT (which is fixed) and pays the difference between Libor and repo rates (which is floating). Historically, however, the floating part of the trade has been rather stable. Duarte et al. (2007) report the average spread between Libor and repo rates of 26.8 bps with a standard deviation of only 13.3 bps. Hence, the profitability of the strategy is primarily driven by the difference between CMS and CMT, which is our spread, $S$, for this strategy:

$$
S=C M S-C M T
$$

(3) TIPS-Treasury bond arbitrage

The objective of this trading strategy is to exploit the relative overvaluation of Treasury bonds as compared to Treasury Inflation-Protected Securities (TIPS), as described in Fleckenstein et al. (2014). The exact strategy involves buying TIPS, entering into receiver inflation swaps for each coupon date, purchasing STRIPS (Separate Trading of Registered Interest and Principal of Securities) to match exactly the coupon payments, and short selling Treasury bonds with the same maturity as TIPS. The main driver of the profitability of this strategy is the 
difference between the sum of STRIPS and TIPS yields and that of Treasury bonds. Thus, we define the spread $S$ as

$$
S=\text { yield }_{\mathrm{STRIPS}}+\text { yield }_{\mathrm{TIPS}}-\text { yield }_{\mathrm{T} \text {-bond }}
$$

When analysing the changes in $S$ for this trading strategy in Equation 2, we use additional control variables, following Fleckenstein et al. (2014). We include the total amount of Treasury and TIPS outstanding to proxy for the supply of bonds, the ratio of total TIPS trading volume by U.S. primary dealers to total coupon-bearing Treasury note and bond trading volume by U.S. primary dealers to capture the relative liquidity of TIPS, and 10-year swap spread to proxy for credit risk.

\section{Data}

\subsection{Bond Yield Data}

The 10-year Treasury yields and Moody's Baa yields are obtained from the H.15 release. Panel A of Table 1 reports the descriptive statistics of the bond yields and their changes. Although the mean Baa spread is 1.5 times larger than that of Treasury bonds (710.90 bps versus 470.14 bps), it has smaller standard deviation (108.89 bps versus 145.89 bps).

$$
\text { [Insert Table } 1 \text { around here] }
$$

\subsection{Hedge Fund Data}

We use a merged hedge fund database, which combines information from five mainstream hedge fund databases (viz. BarclayHedge, EurekaHedge, Hedge Fund Research (HFR), Morningstar, and TASS Lipper).12 The sample period covers 19 years from January 1994 to December 2012. It includes time-series data on monthly net-of-fees returns and AuM, as well as other fund-related static information (such as fees, notice periods, etc.). While merging the data,

\footnotetext{
${ }^{12}$ This is an extended database used in Hodder et al. (2014).
} 
we follow the procedure of Joenvaara et al. (2016). In particular, we first merge management companies based on their names, and then identify funds that are likely to be the same if they belong to the same company and exhibit return correlation higher than $99 \%$ for overlapping returns. For those funds that are found to report to more than one database, we choose the record with the longest reporting history. Moreover, we use only hedge funds which report returns in U.S. dollars.

Hedge fund databases are subject to various biases $\sqrt{13}$ To control for a backfill bias $\sqrt{14}$ we delete the first 12 observations for each hedge fund. We only use funds with more than 24 remaining observations. We further exclude 21 monthly return data points in our sample that were higher than $200 \%$ or less than $-100 \%$. Two hedge funds are removed from our sample due to seemingly unrealistic AuM ${ }^{15}$ The final sample contains 9,725 hedge funds.

Panel B of Table 1 reports the descriptive statistics of the hedge funds in our sample. In general, hedge funds produce a positive average monthly return of $0.61 \%$ with a standard deviation of $4.29 \%$. The average fund size is approximately $\$ 200$ million, with a standard deviation of $\$ 70$ million. The high standard deviation in fund size indicates that funds faced substantial inflow and outflows over the sample period. Half of the funds report the use of leverage. The average management fee is $1.5 \%$ and the performance fee is around $17 \%$. The average lock-up period and notice period are both around one month.

To understand the distribution of the total assets managed by hedge funds, we split funds into quartiles according to their average size. For each year, we form AuM-sorted portfolios. The fund size statistics for each of the portfolios are reported in Table 2, Q1 is the portfolio that includes the $25 \%$ of funds with the largest AuM, while Q4 includes the smallest $25 \%$ of the funds. The statistics are reported for each of the 19 years, as well as for the whole sample period.

The first column reports the total number of hedge funds in our sample for each year. The

\footnotetext{
${ }^{13}$ This includes, for example, self-selection, survivorship, backfill biases (Fung and Hsieh, 2000), as well as deliberately smoothed (Getmansky et al. 2004) and/or misreported returns (Bollen and Pool, 2009).

${ }^{14}$ Fund managers can choose to "backfill" their past performance since inception when they join a database. Such "backfilled" returns are normally reported if they reflect good track record (Fung and Hsieh, 2004).

${ }^{15}$ These two hedge funds are Athena Guaranteed Futures Ltd (TASS number 628) and LG Asian Smaller Companies (TASS number 57686). The single AuM reported for these funds exceeds $\$ 300$ billion, whereas the total AuM of the rest of the hedge funds is less than $\$ 400$ billion during the same period.
} 
number of funds increases steadily from 568 in 1994 and peaks at 5,357 in 2007. It drops thereafter to the levels of 2003-2004, with 3,246 active funds in our dataset, as of 2012. The smaller number of funds is due to investors' withdrawals from hedge funds after substantial losses incurred in the crisis period of 2007-2008, with many funds forced to liquidate due to performance deterioration and the difficulty in maintaining fund operation.

Columns (2) to (5) of Table 2 report the mean and standard deviation of the AuM for the four quartile portfolios, Q1 to Q4. There is a substantial difference between the largest and the smallest funds in terms of their AuM. The average size of funds between 1994 and 2012 is $\$ 851$ million for the Q1 portfolio, while that of the Q4 portfolio is just $\$ 0.2$ million. This indicates that the top $25 \%$ of funds are, on average, over 4,000 times larger than the bottom $25 \%$ of funds. This difference decreases over time; it is likely to be driven by the increasing number of funds. Importantly, the portfolio of the top $25 \%$ of funds controls as much as $89 \%$ of the total AuM as of the end of 2012 .

The last two columns of the table report the total AuM of hedge funds in our sample in USD billion, and the AuM expressed as a percentage of the U.S. GDP as of the end of the previous year. By the end of the sample period, the size of the industry reached $5.35 \%$ of the country's GDP.

[Insert Table 2 around here]

Table 3 reports the descriptive statistics of monthly dollar flow into hedge funds scaled by the U.S. GDP as of the end of the previous year. We report the descriptive statistics of flow to all hedge funds, and separately to bond-trend following funds. Remarkably, the top $25 \%$ of hedge funds attract flows that are more than 10 times larger than the remaining $75 \%$ of funds. Also, within each of the sub-groups (Top or Bottom funds), the outflow from funds with a short notice prior to redemption is more than 10 times larger than that of funds with long notice period. The average outflow from the industry is 8.99 bps of GDP per month. The average outflow from the Top funds with a short notice period is $6.84 \mathrm{bps}$, equivalent to $76 \%$ of the total outflow.

[Insert Table 3 around here] 


\subsection{Fixed Income Arbitrage Strategies Data}

To construct the off-the-run / on-the-run bond spread, we use the constituents of the 30-year government bond index reported in Bloomberg, and use the corresponding ticker to locate an on-the-run bond. When a member of the bond index is changed, we use the previous on-the-run bond ticker as off-the-run bond, and the newly added ticker as an on-the-run bond to compute the difference between the off-the-run and on-the-run bond yields.

To construct the Treasury-swap spread, we use constant maturity Treasury yields, as reported in the H.15 release, and constant-maturity swap rates from Bloomberg. We use six different maturities ranging from 3 months to 10 years. For most maturities, the data are available for the complete sample period from January 1994 to December 2012. For the 3-month maturity, the data are available from 2004 onwards.

To construct the TIPS-Treasury spread, we obtain on-the-run Treasury bond yields, on-therun TIPS yields, and STRIPS from Bloomberg. The yields are reported for fixed, and not constant maturity. Each month, we select the yields of the bonds with the closest maturity to five and thirty years, and compute the difference between the sum of yields of STRIPS and TIPS, and Treasury yield for these two maturities. The 5-year spread can be computed from 1997 onwards, whereas the 30-year spread can be computed only from 2004 onwards, due to earlier data not being available. Table 4 reports the descriptive statistics of the obtained spreads.

[Insert Table 4 around here]

\subsection{Other Control Variables}

Throughout the analysis, we use a set of additional control variables. The levels of the VIX index are obtained from Bloomberg. The noise measure of $\mathrm{Hu}$ et al. (2013) is kindly provided by Jun Pan on the author's web-page ${ }^{16}$ We obtain mutual fund data from the CRSP database. The mutual funds' investment strategies are restricted according to their mandates, which is reflected in the reported fund styles. We use Fixed Income mutual funds only. In particular,

\footnotetext{
${ }^{16} \mathrm{http}: / /$ www.mit.edu/ junpan/
} 
we choose corporate (CRSP Category Code: IC), government (CRSP Category Code: IG), and money market (CRSP Category Code: IM) mutual funds, since these three types of mutual funds focus exclusively on the U.S. bond markets, while others focus on different bond markets, such as emerging markets. To minimize the impact of outliers, we winsorize mutual fund excess returns and percentage flows at the $1 \%$ and $99 \%$ quantiles.

We obtain monthly values of the outstanding amount of TIPS and quarterly value of the outstanding amount of Treasury bonds from Bloomberg 17 The ratio of TIPS to Treasury trading volume by primary dealers is obtained from the Federal Reserve Bank of New York web-page. The 10-year swap spread is collected from Bloomberg. The spread between the yields of Baa- and Aaa-rated bonds and the yield curve slope (the difference between 10-year and 3-month Treasury yields) are computed using the corresponding yields reported in the H.15 release. Panel $\mathrm{C}$ of Table 1 reports the descriptive statistics of all the control variables.

\section{Empirical Results}

\subsection{Fund flows and bond yields}

Table 5 reports the correlation coefficients between changes in dollar flow, changes in bond yields, and other control variables. In general, changes in flows are negatively correlated with changes in bond yields. The correlation coefficient between $\Delta$ DollarFlow $(t-1)$ and changes in Baa yields of -0.17 is substantally larger in absolute value than that with changes in Treasury bond yields of -0.01 . We find that the change in noise $(\Delta$ Noise $)$ is highly correlated with the change in Baa bond yields (0.48), suggesting that bond prices generally decline during periods of low market liquidity. Fund flow itself is highly correlated with inflow and outflow. The corresponding correlation coefficients are 0.85 and -0.89 . This raises the concern regarding multicollinearity, which we alleviate by using only one measure of flow at a time when estimating our regressions.

\section{[Insert Table 5 around here]}

\footnotetext{
${ }^{17}$ Since the outstanding amount of Treasury bonds is available only on quarterly basis, in our regression analysis we use linear interpolation to obtain monthly data.
} 
Table 6 reports the estimation results for Equation (2) for changes in the Treasury bond yield (Panel A), and for changes in the Baa yield (Panel B). Model (1) uses only control variables, Model (2) includes changes in hedge fund flow, and Model (3) also incorporates the interaction between $\Delta$ Noise and $\Delta$ DollarFlow. When including hedge fund flow, the adjusted R-square increases from $9 \%$ to $11 \%$ for changes in Treasury yields, and from $22 \%$ to $23 \%$ for changes in the Baa yields. Changes in hedge fund flow are negatively related to changes in both Treasury and Baa bond yields, supporting our H1 of flow-induced price pressure. The coefficients of -0.322 and -0.273 are statistically significant at the $5 \%$ level. The trading pressure from hedge funds is a viable predictor of the changes in bond yields even after we control for aggregate market liquidity and the availability of arbitrage capital by using the $\Delta$ Noise.

In Model (3), the interaction between changes in noise and changes in flow is not statistically significant for highly liquid Treasury bonds. It is, however, negative and highly significant for changes in Baa yields. The result suggests that the negative impact of flow-induced trading of hedge funds on bond yields is further amplified during periods of low liquidity. Such periods are likely to be associated with increased selling pressure on bond markets. The results are consistent with the intuition of $\mathrm{H} 2$ of fire trades of hedge funds occurring in turbulent times and support the liquidity spiral theory of Brunnermeier and Pedersen (2009).

As for the economic significance of the results, the increase of fund flow by one standard deviation (12.82 bps) leads to an additional decrease in the changes of Treasury bond yields by -4.14 bps, and decrease in Baa yields of -3.60 bps. Furthermore, if fund flow changes during turbulent times when noise increases by one standard deviation (2.40 bps), the changes in Baa yields decrease by additional 5.60 bps. Such changes are economically relevant, given the average monthly change in Treasury bond yield in our sample of -1.73 bps and that of Baa of $-1.29 \mathrm{bps}{ }^{18}$

\section{[Insert Table 6 around here]}

In Table 6, Model (4) tests H3 using inflow, while Model (5) tests H3 using outflow. The results suggest that the link between fund flows and changes in the Treasury bond yields is largely driven by inflows. The corresponding coefficient of -0.641 is significant at the $5 \%$ level.

\footnotetext{
${ }^{18} \mathrm{We}$ summarise the economic impact of flows from this and all the following regression in Table 8 at the end of the current sub-section.
} 
The economic impact of that is that one standard deviation increase in inflow in hedge funds leads to a decline in Treasury bond yield by 4.49 bps during the following month. This relation is not affected by the total amount of arbitrage capital in the economy and market liquidity, as the interaction term with the noise measure is not statistically significant. The results imply that hedge funds are likely to invest in Treasury bonds upon inflow. This may reflect the shortterm "parking" of excess cash into Treasuries. Indeed, from our discussions with hedge fund practitioners we learn that while implementing their investment strategy, hedge funds often hold cash in their portfolio. The use and level of cash varies with investment style and what assets the funds are invested in. Long-only funds, for instance, may retain cash out of tactical considerations. Other styles hold more cash, as the instruments used, for example, forwards, contracts for difference (CFD), options, only require partial funding. Any excess cash in a fund is usually held as free cash or deposited in money market accounts with the fund's custodian or prime broker. If cash is invested and not held as free cash, it is usually invested in U.S. Treasuries or money market funds with the focus on safety, not yield 19

The changes in Baa yields, however, react almost symmetrically on inflow and outflow. The yield decreases upon inflow and increases upon outflow; both effects further amplified during periods of low market liquidity. The impacts of inflow and outflow are also comparable economically. One standard deviation increase in inflows leads to 2.79 bps decline in bond yields, whereas one standard deviation increase in outflows lead to 3.14 bps increase in bond yields.

The upper panel of Table 7 reports the results for inflow and outflow from Top and Bottom funds (H4). Overall, the results are in line with the findings discussed so far, but flows to/from Top funds have stronger statistical support consistent with H4.

[Insert Table 7 around here]

We now select those hedge funds that exhibit a higher than median loading on the bondtrend following factor of Fung and Hsieh (2004). Such funds are likely to engage in bond trading. The results in the bottom panel of Table 7 reveal that flows to/from such bond-trend following funds can be indeed linked to changes in the yields of Baa bonds, but not to changes

\footnotetext{
${ }^{19}$ We would like to thank Stephan Schwill for his helpful comments.
} 
in Treasury bond yields. In fact, one standard deviation increase in the outflow from Top funds results in 3.39 bps increase in Baa yields. An additional 6.15 bps increase in yield follows one standard deviation outflow if the noise measure of $\mathrm{Hu}$ et al. (2013) increases by one standard deviation. These results corroborate our previous conclusion that hedge funds are likely to use the Treasury bond market to (temporarily) allocate free cash upon an inflow. That link is not specific to bond-trend following funds. At the same time, outflow induces funds to sell their assets. Bond-trend following funds are more likely to actually hold large positions in corporate bonds, and thus we do observe a significant link between outflow from bond-trend following funds and Baa yield changes one month ahead.

Table 8 summarises the economic impact of one standard deviation change in flows of different types on bond yields discussed so far, and reveals a noteworthy pattern. Fund flows predict changes in both Treasury and corporate bond yields and are generally negatively related to them. The effect of flow on the corporate bond market is further amplified during periods of low market liquidity, when the noise measure of $\mathrm{Hu}$ et al. (2013) increases. The effect on the Treasury bond market, however, is independent of the level of market liquidity, as we do not find a single case in which the product of $\Delta$ Noise and $\Delta$ Dollar Flow is statistically significant.

[Insert Table 8 around here]

\subsection{Yield convergence in bond-arbitrage trading strategies}

We now move to the analysis of the potential effect of hedge fund flow on the spreads of the commonly used fixed-income arbitrage strategies. Table 9 reports the estimation results for the spreads between the on-the-run and off-the-run 30-year Treasury bonds. Neither the chosen control variables, nor changes in hedge fund flow have significant impact on changes in the spread. The mean yield spread between on-the-run and off-the-run bonds during our sample period is $5.32 \mathrm{bps}$, which is quite small to attract hedge fund interest. This might explain why hedge fund trading does not to lead to convergence in the underlying bond yields.

[Insert Table 9 around here]

Table 10 reports the estimation results for the changes in the spread between constant 
maturity bonds and swap rates. Fund flow is significantly negatively related to changes in spreads for all maturities from 2 to 10 years, apart from the shortest one of 3 months. The mean Treasury-swap spread for the 3-month maturity is $49.7 \mathrm{bps}$, which is slightly higher than the mean spreads for other maturities. At the same time its standard deviation of 47.43 bps is more than twice the average standard deviations of other spreads, which are all around 22 bps. The uncertainty of the gains in this shortest maturity arbitrage strategy might explain the lack of active hedge fund trading. The strongest statistical support is associated with 7-year spreads, which provides a more favourable risk-return trade-off for hedge funds. The coefficient of -0.115 for the total flow is highly significant. The effect is also significant for inflow and outflow, as reported in Panels B and C of Table 10. Hedge funds seem to engage in the longshort strategies betting on the Treasury-swap spread. Upon inflow, funds increase the scale of the strategy. They short more Treasury bonds and enter into more receiver swaps, leading to a decline in the difference between constant maturity swap rate and constant maturity treasury rate.

[Insert Table 10 around here]

The results for the last trading strategy based on TIPS-Treasury spread are reported in Table 11. We consider the spreads for 5- and 30-year maturities. The first column for each maturity includes those control variables that are consistent with the ones used by Fleckenstein et al. (2014). The second column additionally includes all other control variables from Equation (2). With the limited control variables fund flow is significantly negatively related to changes in TIPS-Treasury spread based on 5-year maturity, consistent with the result reported in Fleckenstein et al. (2014). The authors find that TIPS-Treasury mispricing narrows with changes in total global hedge fund net asset values, as estimated by Hedge Fund Research Inc., and interpret this result as supporting their slow-moving capital hypothesis. However, after controlling for other yield determinants, including the noise measure, hedge fund flow is no longer significant for 5-year maturity. This finding suggests that when other control variables are omitted, hedge fund flow captures the overall market sentiment, market liquidity, and other factors that can impact the spread. After controlling for these effects, the remaining flow-induced trading impact on TIPS-Treasury spread based on 5-year maturity is negligible. At the same time, the full specification indicates a strong statistical support for the link between fund flow and 
the TIPS-Treasury spread for 30-year maturity. The results are pronounced for total flow, as well as for inflow and outflow. Flow-induced trading indeed leads to significant changes in the profitability of the strategy and reduces relative mispricing. We thus conclude that hedge funds do exploit TIPS-Treasury mispricing; however, they seem to focus on long-term bonds while implementing this arbitrage strategy.

[Insert Table 11 around here]

\section{Robustness checks}

We perform several robustness checks to assess the stability of our results. We include new control variables, use different scaling on hedge fund and mutual fund flow, assess the model performance across different time periods, consider hedge funds with different lengths of notice period prior to redemption and use the changes in yields of less risky bonds as alternative test assets. Overall, the results are consistent with our main conclusions. We discuss all these robustness checks below, and report the detail results in the supplementary online appendix.

We include two other control variables in the regressions. The first one is a lagged change in the difference between Aaa and Baa bond yields to proxy for changes in credit spread. The second one is a lagged change in the slope of the yield curve measured by the difference in the yields of 10-year Treasury bonds and 3-month Treasury bills. We then include the interaction between these variables and fund flow as additional controls in the regression. The changes slope of the yield curve and the credit spread can capture relative profitability of bonds of different types and may impact the likelihood of hedge funds directing their inflow into particular bonds. The results are not qualitatively difference from the main results, with the additional controls being either not statistically significant or only marginally significant.

To capture the variation of the impact of fund flow on bond yields depending on the market liquidity, in our main analysis we use the interaction term between changes in fund flow and changes in the noise measure of $\mathrm{Hu}$ et al. (2013). We now interact changes in flow with the crisis dummy instead. The crisis dummy is a more crude measure than the noise measure used. Not surprisingly, it is not statistically significant by itself, as reported in Table 6. We also do 
not find any strong statistical support for the interaction of the crisis dummy with changes in flow. It is negative and only marginally significant for inflow, and it is not significant for total flow or outflow.

In the main analysis, we use hedge fund flow scaled by the U.S. GDP as of the previous year. We repeat the tests, scaling flows by the total amount of Treasury bond issued and Corporate bond issued as of the previous year. The magnitude of the estimates does change due to the different scaling of flows, but the results remain qualitatively unchanged.

To assess the stability of the results, we repeat the analysis for two sub-periods. The size of the hedge fund industry has grown substantially since 2003 (see Figure 1), and so we may expect more pronounced results in the later part of the sample. We split the sample into two sub-samples of equal length: from January 1994 to June 2003, and from July 2003 to December 2012 and repeat the analysis for each of the sub-periods. The link between flows and future changes in Treasury bond yield is significant during the second sub-period. As for the link between flow and Baa yield changes, it is pronounced in both sub-periods. However, during the first sub-period, it is the flow itself that is negatively related to yield changes, whereas during the later sub-period, the impact of flow is significant only during times of declining market liquidity.

One of the important contractual terms of hedge funds is a notice period prior to the redemption. Longer notice periods protect fund managers from the adverse consequences of sudden fund outflows. Such funds have more time to raise funds and to offload their positions if necessary. Hence, their outflow should be less informative for prediction of future changes in bond yields. At the same time, flow-performance relation for funds with longer notice periods is expected to be concave for low return regions (Ding et al., 2015). This is due to investor fear of being "stuck" in an underperforming fund for longer period of time. Consequently, funds with long notice periods may exhibit outflow earlier than funds with short notice periods if the macroeconomic environment has just turned unfavorable to hedge funds. This can lead to an opposite effect: that outflow from funds with long notice period have a stronger predictive power for future changes in bond yields.

We divide funds into two groups according to the lengths of their notice periods. A long- 
notice group contains funds with notice periods longer than one month, and a short-notice group includes funds with notice periods shorter than one month. We consider outflows from funds with long and short notice periods separately and repeat the analysis in Equation (2) including the interaction of flow and $\Delta$ Noise. Overall, we find that the economic impact on the Baa yields of outflows from funds with long and short notice periods is similar.

One of the control variables we use in the regressions is percentage flow to bond mutual funds. As a robustness check, we now use dollar mutual fund flow scaled by the GDP instead to make it comparable to our flow specification for hedge funds. We find almost identical results, with dollar mutual fund flows remaining not statistically significant, similar to their percentage counterpart.

Our main analysis focuses on relatively risky Moody's Baa and 10-year Treasury bond yields; and our results are consistent with hedge funds having long positions in these assets and significantly contributing to their price changes. We repeat the analysis for less risky alternatives, expecting the results to weaken if hedge funds indeed focus more on riskier assets. We use changes in Moody's Aaa yields and 3-month Treasury bill yields. Indeed, the relation weakens substantially. Total fund flow has no significant impact on changes in 3-month Treasury bills at all. The loadings on hedge fund flow have the same sign for Aaa yield changes as for Baa, but the results have weaker statistical support. The adjusted R-square for changes in Aaa bond yields is just $9 \%$ compared to $26 \%$ for Baa bond yields. Another key difference is that the product of the noise measure and fund flow is not statistically significant for Aaa bonds, implying that there is no additional effect of bond fire sale by hedge funds during turbulent markets for highly rated bonds.

To more precisely identify the effect of hedge fund trading, one would need to use the information on hedge fund bond holdings, which is not publicly available. We perform an additional indirect check of the plausibility of our findings using the reported equity holdings of hedge fund investment companies. We match 1,050 hedge fund investment companies from our sample to those reporting equity holdings to the Securities and Exchange Commission (SEC) through the $13 \mathrm{~F}$ filings ${ }^{20}$ We then compare the net quarterly fund outflows and the changes in reported equity holdings. We find that, for a median hedge fund company, its net quarterly

\footnotetext{
${ }^{20}$ This sample was previously used in Mattes $(2011)$.
} 
outflow is $\$ 25$ million larger than the corresponding changes in the value of the reported long equity positions. As a result, to meet the redemptions, hedge funds seem to liquidate other assets, together with equity, which may also include fixed income securities. This is consistent with our hypothesis on flow-induced trading and the identified negative relation between flows and future changes of bond yields.

\section{Conclusion}

Hedge funds are important market participants, which can invest in unconventional strategies, take leverage, and short-sell. They invest not only in widely analysed equity markets, but are heavily involved in more specialized fixed income trading too. The size of the industry was above $5 \%$ of the U.S. GDP as of the end of 2012. Hedge funds generally trade for two distinct reasons: portfolio rebalancing or accommodating new inflow and outflows. Since hedge fund bond holdings are not directly observable, we cannot capture the portfolio rebalancing channel. In this paper, we use hedge fund flows to proxy for the flow-induced trading.

We find that fund flow is negatively related to changes in 10-year Treasury bond yield and Moody's Baa yield one month ahead. The effect on Treasury bonds is related to fund inflow, whereas both inflow and outflow lead to changes in the corporate bond yields, consistent with the direct price impact.

The liquidity spiral theory of Brunnermeier and Pedersen (2009) suggests that fund outflow can lead to disproportional price decline in illiquid markets, when investor redemptions lead to fire sales, further price decline, and new redemptions. In support of this conjecture, we find the impact of fund flows on corporate bonds is amplified during periods of decreasing market liquidity.

Hedge funds are not restricted to long only holdings, and hence we consider profitability of several fixed income long-short arbitrage strategies. We do not find any link between fund flow and on-the-run/off-the-run Treasury bond yield spread, suggesting that hedge funds may not be engaging in this type of strategy to a large extent. TIPS-Treasury spread is negatively associated with fund flows, consistent with Fleckenstein et al. (2014). However, when a larger set 
of controls is used in the regressions, fund flow remains highly significant for 30-year maturity, but it loses its significance for 5-year maturity. This indicates that fund flow can be used as a proxy of general market conditions and the amount of arbitrage capital in the economy, and the hedge funds preference for trading riskier and more profitable long maturity bonds in the Treasury markets. Further, fund flow predicts convergence in constant maturity Treasury bond yield and swap rate, for all maturities from 2 to 10 years, making the corresponding Treasury-swap spread arbitrage trading strategies less profitable. These findings indicate that hedge funds do exploit arbitrage opportunities on fixed income markets. Flow-induced trading predicts convergence of the underlying yield spreads and reduces mispricing.

Overall, we present strong statistical evidence that aggregate hedge fund flows (conditional on their direction and fund size) predict bond yield changes, even after the changes in aggregate market and funding liquidity are accounted for. This non-trivial price impact of hedge fund trading in fixed income markets stems from the largest hedge funds. Hedge fund trading on fixed income markets affects not only the investors in the funds, but also all other market participants. Regulators may consider introducing mandatory reporting of bond positions by the largest hedge-fund investment companies, akin to the already existing requirement of equity holdings disclosure in $13 \mathrm{~F}$ filings. This can make fixed income investments more transparent and attractive for other investors, as the risk associated with the price movement due to hedge fund trading can be better assessed. 


\section{References}

Ang, A., S. Gorovyy, and G. B. van Inwegen (2011). Hedge fund leverage. Journal of Financial Economics 102(1), 102-126.

Ben-David, I., F. Franzoni, A. Landier, and R. Moussawi (2013). Do hedge funds manipulate stock prices? The Journal of Finance 68(6), 2383-2434.

Ben-David, I., F. Franzoni, and R. Moussawi (2012). Hedge fund stock trading in the financial crisis of 2007-2009. Review of Financial Studies 25(1), 1-54.

Billio, M., M. Getmansky, A. W. Lo, and L. Pelizzon (2012). Econometric measures of connectedness and systemic risk in the finance and insurance sectors. Journal of Financial Economics 104(3), 535-559.

Bollen, N. P. B. and V. K. Pool (2009). Do Hedge Fund Managers Misreport Returns? Evidence from the Pooled Distribution. The Journal of Finance 64 (5), 2257-2288.

Boyson, N. M., C. W. Stahel, and R. M. Stulz (2010). Hedge fund contagion and liquidity shocks. Journal of Finance 65(5), 1789-1816.

Brunnermeier, M. K. and L. H. Pedersen (2009). Market liquidity and funding liquidity. Review of Financial Studies 22(6), 2201-2238.

Cappiello, L., S. Manganelli, and B. Gerard (2014). Measuring comovements by regression quantiles. Journal of Financial Econometrics 12(4), 645-678.

Cella, C., A. Ellul, and M. Giannetti (2013). Investors' horizons and the amplification of market shocks. The Review of Financial Studies 26(7), 1607-1648. 10.1093/rfs/hht023.

Chan, N., M. Getmansky, S. M. Haas, and A. W. Lo (2005). Systemic risk and hedge funds. NBER Working Paper.

Choi, D., M. Getmansky, B. Henderson, and H. Tookes (2010). Convertible bond arbitrageurs as suppliers of capital. Review of Financial Studies 23(6), 2492-2522.

Coval, J. and E. Stafford (2007). Asset fire sales (and purchases) in equity markets. Journal of Financial Economics 86(2), 479-512. 
Ding, B., M. Getmansky, B. Liang, and R. R. Wermers (2015). Investor flows and share restrictions in the hedge fund industry. Working Paper.

Duarte, J., F. A. Longstaff, and F. Yu (2007). Risk and return in fixed-income arbitrage: Nickels in front of a steamroller? The Review of Financial Studies 20(3), 769-811.

Dudley, E. and M. Nimalendran (2011). Margins and hedge fund contagion. Journal of Financial and Quantitative Analysis 46, 1227-1257.

Financial Services Authority (2010a). Assessing possible sources of systemic risk from hedge funds - A report on the findings of the hedge fund as counterparty survey and hedge fund survey, 2010a. Technical Report.

Financial Services Authority (2010b). Assessing possible sources of systemic risk from hedge funds - A report on the findings of the hedge fund survey and hedge fund as counterparty survey, 2010b. Technical Report.

Financial Services Authority (2011). Assessing the possible sources of systemic risk from hedge funds - A report on the findings of the hedge fund survey and hedge fund as counterparty survey, 2011. Technical Report.

Fleckenstein, M., F. A. Longstaff, and H. Lustig (2014). The TIPS-Treasury Bond Puzzle. The Journal of Finance 69(5), 2151-2197.

Fung, W. and D. Hsieh (2000). Performance characteristics of hedge funds and commodity funds: Natural vs. spurious biases. Journal of Financial and Quantitative Analysis 35(3), 291-307.

Fung, W. and D. A. Hsieh (2004). Hedge fund benchmarks: A risk-based approach. Financial Analysts Journal 60(5), 65-80.

Getmansky, M., A. W. Lo, and I. Makarov (2004). An econometric model of serial correlation and illiquidity in hedge fund returns. Journal of Financial Economics 74(3), 529-609.

Hodder, J. E., J. C. Jackwerth, and O. Kolokolova (2014). Recovering delisting returns of hedge funds. Journal of Financial and Quantitative Analysis 49(3), 797-815. 
Hu, G. X., J. Pan, and J. Wang (2013). Noise as information for illiquidity. Journal of Finance 68(6), 2341-2382.

Jiao, Y. (2013). Hedge funds and equity prices. Review of Finance 17(3), 1141-1177.

Joenvaara, J., R. Kosowski, and P. Tolonen (2014). The effect of investment constraints on hedge fund investor returns. Working paper.

Joenvaara, J., R. Kosowski, and P. Tolonen (2016). Hedge fund performance: What do we know? Working Paper.

Jylha, P., K. Rinne, and M. Suominen (2014). Do hedge funds supply or demand liquidity? Review of Finance 18(4), 1259-1298.

Kang, N., P. Kondor, and R. Sadka (2014). Do hedge funds reduce idiosyncratic risk? Journal of Financial and Quantitative Analysis 49(04), 843-877.

Khandani, A. E. and A. W. Lo (2007). What happened to the quants in August 2007? Journal of Investment Management 5, 5-54.

Khandani, A. E. and A. W. Lo (2011). What happened to the quants in August 2007? Evidence from factors and transactions data. Journal of Financial Markets 14(1), 1-46.

Krishnamurthy, A. (2002). The bond/old-bond spread. Journal of Financial Economics 66(23), 463-506.

Kruttli, M. S., A. J. Patton, and T. Ramadorai (2015). The impact of hedge funds on asset markets. The Review of Asset Pricing Studies 5(2), 185-226.

Mattes, A. (2011). Hedge fund herding. Working Paper.

Sadka, R. (2010). Liquidity risk and the cross-section of hedge-fund returns. Journal of Financial Economics 98(1), 54-71.

Teo, M. (2011). The liquidity risk of liquid hedge funds. Journal of Financial Economics 100(1), $24-44$. 
Table 1: Data Descriptive Statistics

The table reports the descriptive statistics of the data in our sample from 1994 to 2012. Panel A covers 10-year Treasury bond yields (TB10Y) and Moody's Baa bond yields (Baa) in basis points and their monthly changes (denoted by $\Delta$ ). Panel B describes our hedge fund sample including fund return (Ret, in percent per month), assets under management (AuM, in million USD), dollar flow (in million USD), usage of a high-water mark (HWM), usage of leverage (Lev), management fee (MgmtFee in percent), performance fee (PerfFee in percent), lock-up period (in months), and notice period prior to redemption (in months). Panel $\mathrm{C}$ reports the descriptive statistics of the control variables. MFExRet and MFFlow are monthly excess return (in percent per month) and monthly flows (in percent per month) of fixed income mutual funds in our sample. VIX is the CBOE VIX index. Noise is the Hu et al. (2013) noise measure. TIPS_OUT and TR_OUT are the outstanding amounts of TIPS and Treasury, respectively. TIPS\TR is the relative trading volume by primary dealers in TIPS versus Treasury

\begin{tabular}{|c|c|c|c|c|c|c|c|c|}
\hline & Mean & Median & STD & Skewness & Kurtosis & Min & Max & $\mathrm{N}$ obs \\
\hline \multicolumn{9}{|c|}{ Panel A: Bond yields } \\
\hline TB10Y & 470.14 & 462.50 & 145.89 & -0.10 & 2.52 & 151.00 & 791.00 & 226 \\
\hline$\Delta \mathrm{TB} 10 \mathrm{Y}$ & -1.73 & -1.00 & 27.66 & 0.01 & 4.02 & -108.00 & 95.00 & 226 \\
\hline Baa & 710.90 & 719.00 & 108.89 & -0.22 & 2.29 & 445.00 & 954.00 & 226 \\
\hline$\Delta \mathrm{Baa}$ & -1.29 & -2.00 & 24.36 & 1.35 & 13.70 & -96.00 & 169.00 & 226 \\
\hline \multicolumn{9}{|c|}{ Panel B: Hedge fund data } \\
\hline $\operatorname{Ret}(\%)$ & 0.61 & 0.57 & 4.29 & 0.46 & 17.21 & -8.76 & 12.04 & 9,725 \\
\hline $\mathrm{AuM}(\$ \mathrm{M})$ & 204.33 & 24.55 & 69.90 & 44.63 & $2,652.40$ & 0.00 & $120,866.38$ & 9,725 \\
\hline Dollar Flow $(\$ M)$ & 1.06 & 0.00 & 12.93 & 74.03 & $6,716.33$ & -633.52 & $2,955.34$ & 9,725 \\
\hline HWM & 0.74 & 1.00 & 0.44 & -1.09 & 2.19 & 0.00 & 1.00 & 9,263 \\
\hline Lev & 0.48 & 0.00 & 0.50 & 0.10 & 1.01 & 0.00 & 1.00 & 7,329 \\
\hline MgmtFee (\%) & 1.49 & 1.50 & 0.66 & 4.47 & 95.64 & 0.00 & 20.00 & 9,412 \\
\hline PerfFee (\%) & 17.43 & 20.00 & 6.76 & -1.08 & 7.07 & 0.00 & 65.00 & 9,432 \\
\hline Lockup (Months) & 0.91 & 0.00 & 3.88 & 6.34 & 62.08 & 0.00 & 84.00 & 9,725 \\
\hline Notice (Months) & 0.60 & 0.00 & 1.70 & 4.98 & 32.01 & 0.00 & 18.00 & 9,725 \\
\hline \multicolumn{9}{|c|}{ Panel C: Control variables } \\
\hline MFExRet (\%) & -0.07 & -0.15 & 1.06 & -0.88 & 31.15 & -17.69 & 12.13 & 746,336 \\
\hline MFFlow (\%) & 1.58 & -0.20 & 13.58 & 3.06 & 20.73 & -50.12 & 132.04 & 712,226 \\
\hline VIX & 0.03 & -0.17 & 4.47 & 0.80 & 4.78 & -15.28 & 20.50 & 228 \\
\hline Noise (bps) & 3.26 & 2.68 & 2.40 & 3.82 & 18.35 & 0.79 & 17.50 & 228 \\
\hline TIPS_OUT (\$Tril) & 309.44 & 266.35 & 246.52 & 0.47 & -1.13 & 7.36 & 849.84 & 191 \\
\hline TR_OUT (\$Tril) & $5,890.75$ & $4,578.02$ & $2,494.17$ & 1.44 & 0.81 & $3,772.27$ & $12,822.90$ & 228 \\
\hline $\mathrm{TIPS} \backslash \mathrm{TR}$ & 0.01 & 0.01 & 0.01 & 0.18 & -0.90 & 0.00 & 0.03 & 180 \\
\hline BaaAaa (bps) & 98.34 & 87.50 & 46.50 & 2.94 & 11.01 & 53.00 & 343.00 & 228 \\
\hline Slope (bps) & 165.35 & 160.00 & 120.31 & -0.05 & -1.15 & -77.00 & 379.00 & 228 \\
\hline 10YSwap (bps) & 47.68 & 43.50 & 27.50 & 0.68 & 0.59 & -1.63 & 135.90 & 228 \\
\hline
\end{tabular}


Table 2: Fund Size in the AuM-Sorted Portfolios

The table reports the fund sizes of the AuM-sorted portfolios. Each year, individual hedge funds are sorted into four groups according to their average AuM in that year, with Q1 being a portfolio containing the largest $25 \%$ of funds, and Q4 containing $25 \%$ of smallest funds. The table reports the mean and standard deviation of fund size for the four groups. The last row summarizes the mean and standard deviation of fund sizes in the four groups based on the whole sample period. Columns (6) and (7) report the total size of all hedge funds in our sample in billions USD and in percent relative to the U.S. GDP as of the end of the previous year.

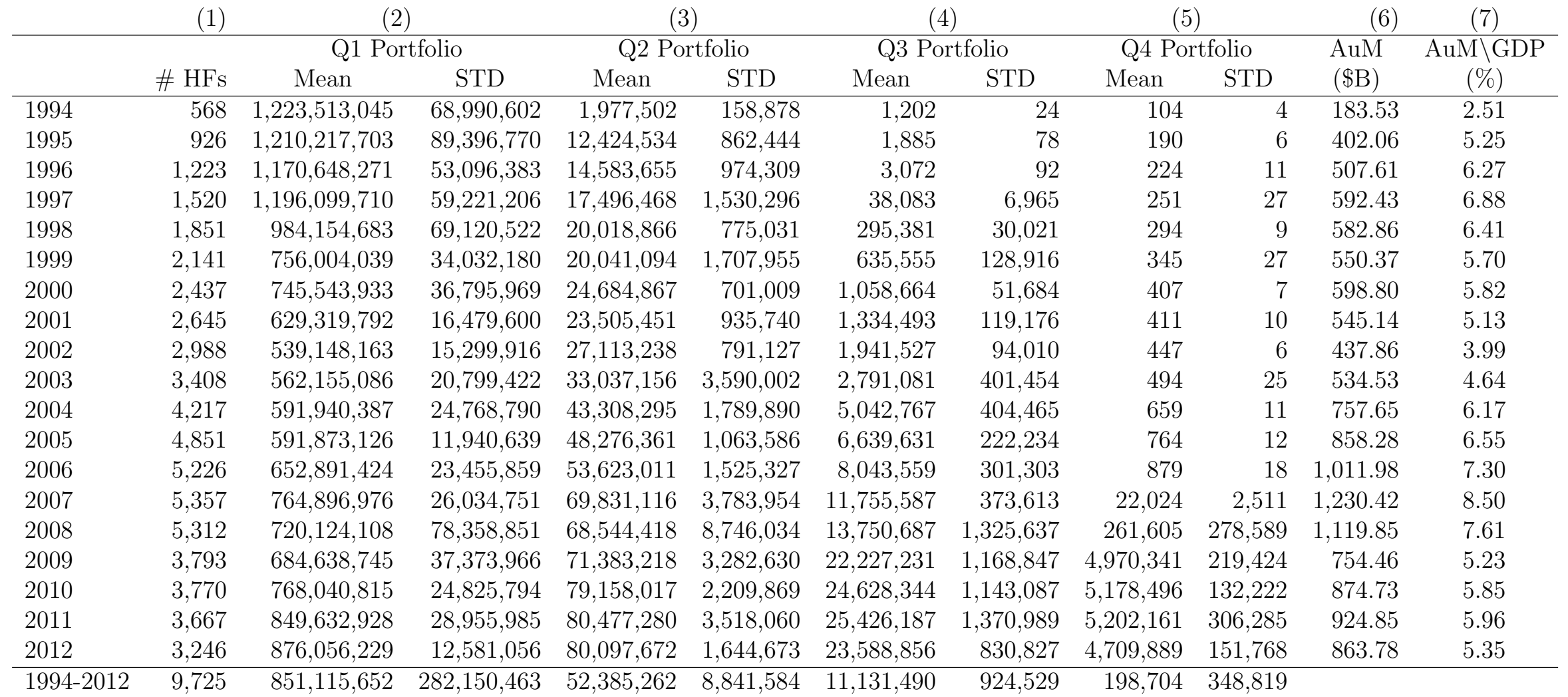


Table 3: Dollar Fund Flow (Scaled by GDP): Descriptive Statistics

The table reports the mean and standard deviation (STD) of monthly dollar flow into the hedge fund industry expressed in basis points (bps) of the U.S. GDP. "Bond HFs" stands for those hedge funds with the above median loading on the bond-trend following factor of Fung and Hsieh (2004). "Flow" is a net dollar flow into the funds, "Inflow" and "Outflow" are positive and negative constituents of the net flow, respectively. "Top" stands for the largest $25 \%$ of funds. "Bottom" stands for the remaining $75 \%$ of funds. "Long (Short) Notice" indicates funds with the notice period prior to redemption longer (shorter) than one month.

\begin{tabular}{lrrrr}
\hline & \multicolumn{2}{c}{ All } & HFs & \multicolumn{2}{c}{ Bond } & HFs \\
& Mean & STD & Mean & STD \\
\hline Flow & 3.01 & 12.82 & 1.56 & 7.51 \\
Inflow & 12.00 & 7.00 & 6.52 & 4.27 \\
Outflow & 8.99 & 9.07 & 4.96 & 4.72 \\
Top Inflow & 9.97 & 6.07 & 5.33 & 3.81 \\
Top Outflow & 7.27 & 7.03 & 3.91 & 3.62 \\
Bottom Inflow & 0.94 & 0.73 & 0.46 & 0.34 \\
Bottom Outflow & 0.61 & 0.75 & 0.29 & 0.33 \\
Top, Long Notice, Out & 0.43 & 0.58 & 0.19 & 0.33 \\
Top, Short Notice Out & 6.84 & 6.58 & 3.72 & 3.48 \\
Bottom, Long Notice, Out & 0.05 & 0.07 & 0.02 & 0.03 \\
Bottom, Short Notice Out & 0.57 & 0.69 & 0.27 & 0.30 \\
\hline
\end{tabular}


Table 4: Fixed Income Spreads: Descriptive Statistics

The table reports the descriptive statistics of yield spreads underlying three fixed income arbitrage strategies, expressed in basis points (bps). We use (1) Off-the-run/on-the-run bond yield spread, (2) Treasury-swap spread, and (3) TIPS-Treasury spread. The detailed strategy description can be found in Section 3.6 .

\begin{tabular}{|c|c|c|c|c|c|c|c|c|c|c|}
\hline & & Mean & Median & STD & Skewness & Kurtosis & Min & Max & $\mathrm{N}$ obs & Data span \\
\hline Off-the-run/on-the-run spread & 30-year & 5.32 & 4.90 & 4.86 & 0.38 & -0.73 & -3.00 & 18.20 & 228 & 1994-2012 \\
\hline \multirow{6}{*}{ Treasury-swap spread } & 3-month & 49.70 & 33.97 & 47.43 & 2.70 & 9.51 & 12.73 & 312.57 & 110 & $2003-2012$ \\
\hline & 2-year & 39.23 & 35.50 & 21.14 & 1.43 & 3.18 & 9.45 & 144.70 & 228 & 1994-2012 \\
\hline & 3-year & 44.63 & 40.18 & 22.71 & 1.26 & 2.40 & 9.99 & 146.45 & 228 & $1994-2012$ \\
\hline & 5-year & 46.41 & 41.50 & 22.18 & 0.86 & -0.00 & 10.60 & 110.73 & 228 & 1994-2012 \\
\hline & 7-year & 43.16 & 39.50 & 22.02 & 0.78 & 0.20 & 4.10 & 111.30 & 228 & 1994-2012 \\
\hline & 10-year & 45.79 & 42.50 & 27.54 & 0.67 & 0.63 & -4.65 & 134.10 & 228 & 1994-2012 \\
\hline \multirow[t]{2}{*}{ TIPS-Treasury spread } & 5-year & 174.75 & 165.61 & 159.79 & -0.18 & -0.93 & -148.48 & 421.20 & 186 & $1997-2012$ \\
\hline & 30-year & 180.40 & 195.35 & 59.17 & -1.03 & 0.79 & 30.72 & 315.87 & 105 & 2004-2012 \\
\hline
\end{tabular}


Table 5: Factor Correlations

The table reports the correlation coefficients over the sample period from 1994 to 2012 between various variables used in this study. $\triangle$ indicates monthly changes. Baa is the Moody's Baa yield, TB10Y is the U.S. 10-year Treasury yield. VIX is the CBOE VIX index, MFExRet is the excess return of bond-oriented mutual funds, MFFlow is the percentage fund flow of bond-oriented mutual funds, HFExRet is the excess return of hedge funds, DollarFlow is hedge fund flow scaled by the U.S. GDP. DollarInflow is the aggregate dollar inflow and DollarOutflow is the aggregate dollar outflow, both scaled by the U.S. GDP.

\begin{tabular}{rrrrrrrrrrr}
\hline & & $(1)$ & $(2)$ & $(3)$ & $(4)$ & $(5)$ & $(6)$ & $(7)$ & $(8)$ & $(9)$ \\
\hline$(1)$ & $\Delta$ Baa (t) & & & & & & & & & \\
$(2)$ & $\Delta$ TB10Y (t) & 0.64 & & & & & & & & \\
$(3)$ & $\Delta$ VIX (t) & 0.23 & -0.17 & & & & & & & \\
$(4)$ & $\Delta$ Noise (t) & 0.48 & 0.07 & 0.37 & & & & & & \\
$(5)$ & MFExRet(t-1) & -0.04 & 0.06 & -0.08 & -0.05 & & & & & \\
$(6)$ & MFFlow(t-1) & 0.06 & -0.08 & -0.05 & 0.11 & -0.41 & & & & \\
$(7)$ & HFExRet(t-1) & -0.07 & 0.19 & 0.03 & -0.15 & 0.56 & -0.51 & & & \\
$(8)$ & $\Delta$ DollarFlow(t-1) & -0.17 & -0.01 & -0.02 & -0.14 & 0.08 & -0.20 & 0.53 & & \\
$(9)$ & $\Delta$ DollarInflow(t-1) & -0.09 & -0.01 & 0.07 & -0.05 & 0.04 & -0.14 & 0.53 & 0.85 & \\
$(10)$ & $\Delta$ DollarOutflow(t-1) & 0.20 & 0.01 & 0.08 & 0.17 & -0.09 & 0.21 & -0.40 & -0.89 & -0.51 \\
\hline
\end{tabular}


Table 6: Hedge Fund Dollar Flow

The table reports the results based on total hedge fund flow, as well as inflow and outflow from 1994 to 2012 . Baa is the Moody's Baa yield, TB10Y is the U.S. 10-year Treasury yield. $D_{C r i s i s}$ is a dummy variable taking a value of 1 from July 2007 to February 2009 , or 0 for the rest of the sample period. Lag1 is the previous value of the corresponding dependent variable. VIX is the CBOE VIX index, Noise is the noise measure of Hu et al. (2013), MFExRet is the excess return of bond-oriented mutual funds, $M F F l o w$ is the percentage fund flow of bond-oriented mutual funds, HFExRet is the excess return of hedge funds, and DollarFlow is hedge fund flow scaled by the U.S. GDP as of the end of the previous year. $\Delta$ indicates monthly changes in the corresponding variable. Newey-West t-statistics are reported in brackets. ${ }^{*}, * *, * *$ indicate significance at the 10,5 , and $1 \%$ level, respectively.

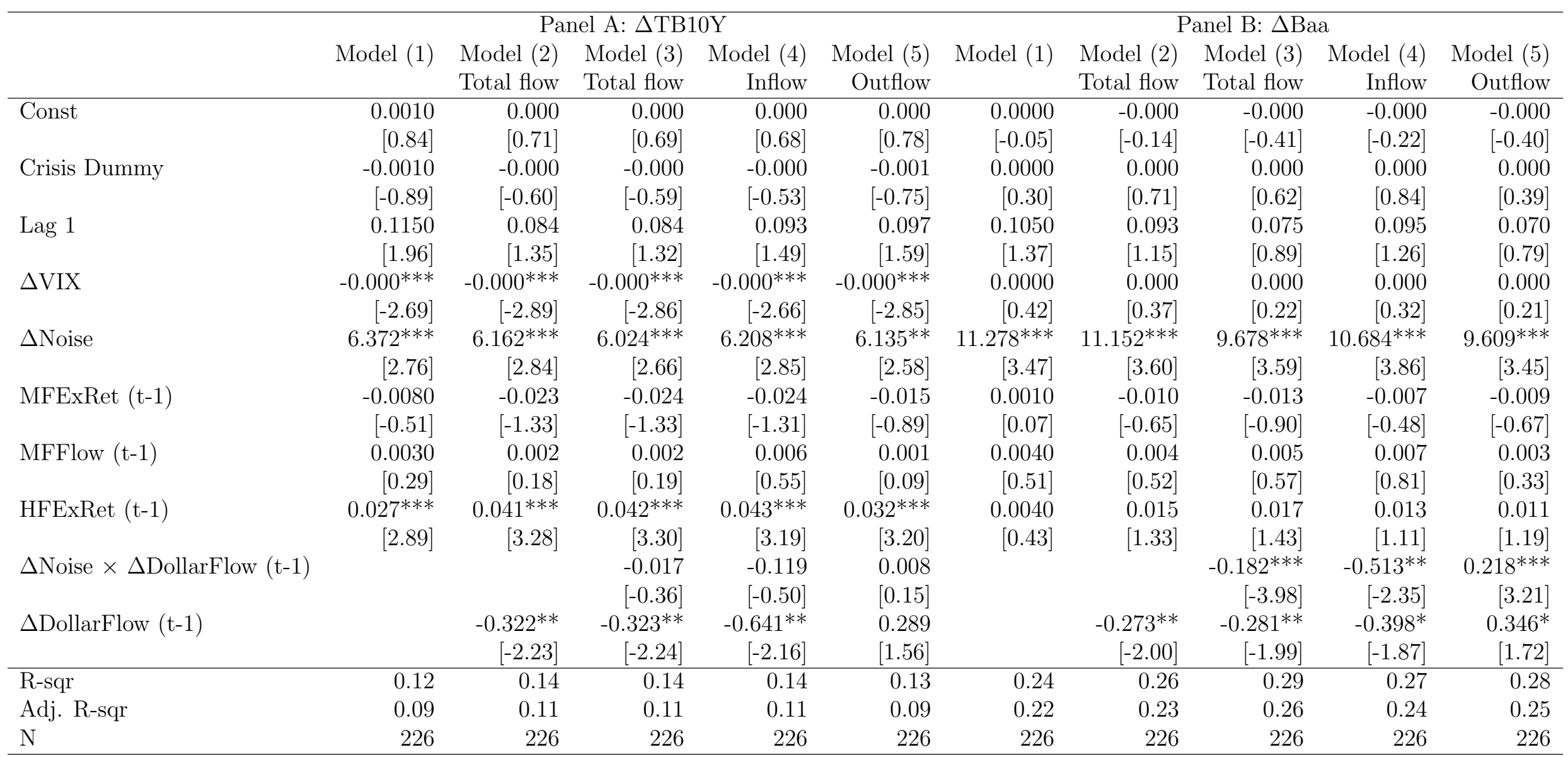


Table 7: Inflow and Outflow from Top and Bottom Funds

This table reports the results based on inflow and outflow from Top and Bottom funds separately from 1994 to 2012 . Top funds are the largest $25 \%$ of hedge funds and Bottom are the remaining hedge funds. Baa is the Moody's Baa yield, TB10Y is the U.S. 10-year Treasury yield. Noise is the noise measure of Hu et al. (2013), and DollarFlow is hedge fund in- or outflow scaled by the U.S. GDP as of the end of the previous year. $\Delta$ indicates monthly changes in the corresponding variable. The upper panel is based on all hedge funds. The lower panel is based on flows to hedge funds with higher than median loading on the bond-trend following factor of Fung and Hsieh (2004). Newey-West t-statistics are reported in brackets. ${ }^{*}, * *, * * *$ indicate significance at the 10, 5, and $1 \%$ level, respectively.

\begin{tabular}{|c|c|c|c|c|c|c|c|c|}
\hline & \multicolumn{4}{|c|}{ Panel A: $\Delta$ TB10Y } & \multicolumn{4}{|c|}{ Panel B: $\Delta$ Baa } \\
\hline & \multicolumn{2}{|c|}{ Inflow } & \multicolumn{2}{|c|}{ Outflow } & \multicolumn{2}{|c|}{ Inflow } & \multicolumn{2}{|c|}{ Outflow } \\
\hline & Top & Bottom & Top & Bottom & Top & Bottom & Top & Bottom \\
\hline & \multicolumn{8}{|c|}{ All hedge funds } \\
\hline \multirow{2}{*}{$\Delta$ Noise $\times \Delta$ DollarFlow $(\mathrm{t}-1)$} & -0.144 & -6.368 & 0.018 & 0.579 & $-0.552^{* *}$ & $-8.415^{*}$ & $0.286^{* * *}$ & 4.896 \\
\hline & {$[-0.44]$} & {$[-1.35]$} & {$[0.29]$} & {$[0.29]$} & {$[-2.06]$} & {$[-1.68]$} & {$[2.90]$} & [1.27] \\
\hline \multirow[t]{2}{*}{$\Delta$ DollarFlow $(\mathrm{t}-1)$} & $-0.703^{* *}$ & $-9.265^{*}$ & $0.591^{*}$ & -0.083 & -0.359 & $-6.834^{*}$ & 0.503 & 2.403 \\
\hline & {$[-2.00]$} & {$[-1.85]$} & {$[1.71]$} & {$[-0.01]$} & {$[-1.55]$} & {$[-1.96]$} & [1.40] & {$[0.76]$} \\
\hline Controls & yes & yes & yes & yes & yes & yes & yes & yes \\
\hline R-sqr & 0.14 & 0.14 & 0.14 & 0.12 & 0.26 & 0.27 & 0.29 & 0.26 \\
\hline Adj. R-sqr & 0.11 & 0.11 & 0.10 & 0.09 & 0.23 & 0.24 & 0.26 & 0.23 \\
\hline \multirow[t]{2}{*}{$\mathrm{N}$} & 226 & 226 & 226 & 226 & 226 & 226 & 226 & 226 \\
\hline & \multicolumn{8}{|c|}{ Bond-trend following hedge funds } \\
\hline \multirow{2}{*}{$\Delta$ Noise $\times \Delta$ DollarFlow $(\mathrm{t}-1)$} & -0.036 & -14.121 & 0.159 & 0.394 & -0.530 & $-22.909 * *$ & $0.708^{* * *}$ & 13.504 \\
\hline & {$[-0.06]$} & {$[-1.53]$} & [0.87] & {$[0.09]$} & {$[-1.14]$} & {$[-2.42]$} & [3.19] & {$[1.48]$} \\
\hline \multirow[t]{2}{*}{$\Delta$ DollarFlow $(\mathrm{t}-1)$} & $-0.815^{*}$ & -15.218 & 0.854 & 7.608 & -0.364 & $-12.209^{*}$ & $0.936^{*}$ & 8.337 \\
\hline & {$[-1.82]$} & {$[-1.31]$} & {$[1.52]$} & {$[0.66]$} & {$[-1.25]$} & {$[-1.68]$} & {$[1.77]$} & [1.22] \\
\hline Controls & yes & yes & yes & yes & yes & yes & yes & yes \\
\hline R-sqr & 0.14 & 0.14 & 0.13 & 0.13 & 0.25 & 0.27 & 0.29 & 0.27 \\
\hline Adj. R-sqr & 0.10 & 0.10 & 0.10 & 0.09 & 0.22 & 0.24 & 0.26 & 0.24 \\
\hline $\mathrm{N}$ & 226 & 226 & 226 & 226 & 226 & 226 & 226 & 226 \\
\hline
\end{tabular}


Table 8: Economic Impact of Fund Flows on Bond Yields

The table reports the expected economic impact (in basis points) on changes in the U.S. 10-year Treasury yield (TB10Y) and the Moody's Baa yield (Baa) by one standard deviation increase in hedge fund monthly dollar flow (DollarFlow) and one standard deviation increase in dollar flow together with one standard deviation increase of the noise measure of $\mathrm{Hu}$ et al. (2013) (Noise\&DollarFlow). Top funds are the largest $25 \%$ of hedge funds and Bottom are the remaining hedge funds.

\begin{tabular}{|c|c|c|c|c|}
\hline \multirow[b]{2}{*}{1 STD change in: } & \multicolumn{2}{|c|}{ Panel A: $\Delta$ TB10Y } & \multicolumn{2}{|c|}{ Panel B: $\Delta$ Baa } \\
\hline & DollarFlow & $\begin{array}{c}\text { Noise \& } \\
\text { DollarFlow }\end{array}$ & DollarFlow & $\begin{array}{c}\text { Noise \& } \\
\text { DollarFlow }\end{array}$ \\
\hline Flow & -4.14 & - & -3.60 & -5.60 \\
\hline Inflow & -4.49 & - & -2.79 & -8.62 \\
\hline Outflow & - & - & 3.14 & 4.75 \\
\hline Top Inflow & -4.27 & - & - & -8.04 \\
\hline Bottom Inflow & -6.76 & - & -4.99 & -14.74 \\
\hline Top Outflow & 4.15 & - & - & 4.83 \\
\hline Bottom Outflow & - & - & - & - \\
\hline Top Outflow, Long Notice & 3.55 & - & - & 4.71 \\
\hline Top Outflow, Short Notice & - & - & - & 4.93 \\
\hline Bond HFs, Inflow, Top & -3.11 & - & - & - \\
\hline Bond HFs, Inflow, Bottom & - & - & -4.15 & -18.69 \\
\hline Bond HFs, Outflow, Top & - & - & 3.39 & 6.15 \\
\hline Bond HFs, Outflow, Bottom & - & - & - & - \\
\hline
\end{tabular}


Table 9: On-the-run/ Off-the-run Bond Spread

The table reports the estimation results of the regression for the changes in the spread between on-the-run and the most current off-the-run 30-year bond yields. The control variables are the ones used in Table 6. DollarFlow is hedge fund flow scaled by the U.S. GDP as of the end of the previous year. "Total" indicates that total net dollar flow is used, "Inflow" and "Outflow" indicate the use of inflow and outflow respectively. $\Delta$ indicates monthly changes in the corresponding variable. Newey-West t-statistics are reported in brackets. $* * * * * *$ indicate significance at the 10,5 , and $1 \%$ level, respectively.

\begin{tabular}{lrrr}
\hline & Total flow & Inflow & Outflow \\
\hline Const & 0.000 & 0.000 & 0.000 \\
& {$[1.05]$} & {$[1.01]$} & {$[1.09]$} \\
Crisis Dummy & -0.000 & -0.000 & -0.000 \\
& {$[-0.80]$} & {$[-0.72]$} & {$[-0.90]$} \\
Lag 1 & 0.007 & 0.007 & 0.008 \\
& {$[1.49]$} & {$[1.46]$} & {$[1.58]$} \\
$\Delta$ VIX & 0.000 & 0.000 & 0.000 \\
& {$[0.63]$} & {$[0.66]$} & {$[0.66]$} \\
$\Delta$ Noise & 0.103 & 0.104 & 0.107 \\
& {$[0.70]$} & {$[0.72]$} & {$[0.73]$} \\
MFExRet (t-1) & 0.002 & 0.002 & 0.002 \\
& {$[1.25]$} & {$[1.08]$} & {$[1.47]$} \\
MFFlow (t-1) & 0.002 & 0.002 & 0.002 \\
& {$[1.23]$} & {$[1.32]$} & {$[1.25]$} \\
HFExRet (t-1) & -0.000 & -0.000 & -0.001 \\
& {$[-0.45]$} & {$[-0.13]$} & {$[-0.69]$} \\
$\Delta$ DollarFlow (t- 1$)$ & -0.003 & -0.016 & -0.004 \\
& {$[-0.26]$} & {$[-0.70]$} & {$[-0.29]$} \\
\hline R-sqr & 0.03 & 0.03 & 0.03 \\
Adj. R-sqr & -0.01 & -0.00 & -0.01 \\
N & 226 & 226 & 226 \\
\hline
\end{tabular}


Table 10: Constant Maturity - Swap Spread

The table reports the estimation results of the regression for the changes in the spread between constant maturity swap rate and constant maturity Treasury rate. 3-month, 2-, 3-, 5-, 7-, and 10-year tenors are used. The control variables are those used in Table 6. DollarFlow is hedge fund flow scaled by the U.S. GDP as of the end of the previous year. "Total flow" indicates that total net dollar flow is used, "Inflow" and "Outflow" indicate the use of inflow and outflow respectively. $\Delta$ indicates monthly changes in the corresponding variable. Newey-West t-statistics are reported in brackets. $*, *, * * *$ indicate significance at the 10,5 , and $1 \%$ level, respectively.

\begin{tabular}{|c|c|c|c|c|c|c|}
\hline & 3-month & 2-year & 3-year & 5-year & 7-year & 10 -year \\
\hline & \multicolumn{6}{|c|}{ Panel A: Total flow } \\
\hline \multirow[t]{2}{*}{ Const } & -0.000 & $-0.000^{*}$ & $-0.000^{*}$ & $-0.000^{*}$ & -0.000 & -0.000 \\
\hline & {$[-0.44]$} & {$[-1.92]$} & {$[-1.79]$} & {$[-1.69]$} & {$[-1.51]$} & {$[-1.13]$} \\
\hline \multirow[t]{2}{*}{ Crisis Dummy } & -0.000 & 0.000 & 0.000 & 0.000 & -0.000 & -0.000 \\
\hline & {$[-0.36]$} & {$[0.53]$} & {$[0.34]$} & {$[0.37]$} & {$[-0.31]$} & {$[-0.21]$} \\
\hline \multirow[t]{2}{*}{ Lag 1} & $-0.363^{* * *}$ & $-0.273^{* * *}$ & -0.109 & $-0.165^{* *}$ & $-0.166^{*}$ & -0.137 \\
\hline & {$[-2.91]$} & {$[-3.68]$} & {$[-1.21]$} & [-2.09] & {$[-1.94]$} & {$[-1.63]$} \\
\hline \multirow[t]{2}{*}{$\Delta \mathrm{VIX}$} & 0.000 & $0.000^{* *}$ & $0.000^{* *}$ & $0.000 * * *$ & $0.000 * * *$ & 0.000 \\
\hline & [1.06] & {$[2.06]$} & {$[2.48]$} & {$[2.62]$} & [3.30] & {$[1.45]$} \\
\hline \multirow[t]{2}{*}{$\Delta$ Noise } & 2.856 & 1.793 & $2.178^{* *}$ & $1.608^{*}$ & $1.284^{* *}$ & -0.113 \\
\hline & {$[0.67]$} & {$[1.55]$} & {$[2.53]$} & [1.82] & {$[2.02]$} & [-0.13] \\
\hline \multirow[t]{2}{*}{ MFExRet (t-1) } & -0.007 & $-0.014^{* * *}$ & $-0.014^{* * *}$ & $-0.012^{* * *}$ & $-0.015^{* * *}$ & $-0.012^{* *}$ \\
\hline & {$[-0.29]$} & {$[-3.12]$} & {$[-3.92]$} & {$[-2.60]$} & {$[-3.11]$} & {$[-2.51]$} \\
\hline \multirow[t]{2}{*}{ MFFlow (t-1) } & -0.016 & -0.004 & -0.002 & -0.002 & -0.001 & -0.002 \\
\hline & {$[-0.71]$} & {$[-0.83]$} & [-0.43] & {$[-0.46]$} & {$[-0.21]$} & {$[-0.43]$} \\
\hline \multirow[t]{2}{*}{ HFExRet (t-1) } & -0.005 & $0.008^{* *}$ & $0.010^{* * *}$ & $0.007^{*}$ & $0.011^{* * *}$ & $0.010^{* * *}$ \\
\hline & {$[-0.20]$} & {$[2.15]$} & {$[2.76]$} & [1.90] & [3.09] & [2.81] \\
\hline \multirow[t]{2}{*}{$\Delta$ DollarFlow $(\mathrm{t}-1)$} & -0.203 & $-0.108 * *$ & $-0.086^{* *}$ & $-0.068^{*}$ & $-0.115^{* * *}$ & $-0.121^{* *}$ \\
\hline & {$[-0.81]$} & {$[-2.11]$} & {$[-2.33]$} & {$[-1.82]$} & {$[-3.14]$} & {$[-2.54]$} \\
\hline R-sqr & 0.16 & 0.20 & 0.22 & 0.19 & 0.22 & 0.10 \\
\hline Adj. R-sqr & 0.10 & 0.17 & 0.19 & 0.16 & 0.19 & 0.07 \\
\hline \multirow[t]{2}{*}{$\mathrm{N}$} & 116 & 226 & 226 & 226 & 226 & 226 \\
\hline & \multicolumn{6}{|c|}{ Panel B: Inflow } \\
\hline \multirow[t]{2}{*}{$\Delta$ DollarFlow $(\mathrm{t}-1)$} & -0.558 & -0.151 & -0.181 & -0.078 & $-0.167^{*}$ & $-0.302^{* * *}$ \\
\hline & {$[-1.56]$} & {$[-1.41]$} & {$[-1.61]$} & {$[-0.78]$} & {$[-1.84]$} & {$[-3.25]$} \\
\hline Controls & yes & yes & yes & yes & yes & yes \\
\hline Adj. R-sqr & 0.10 & 0.16 & 0.20 & 0.15 & 0.17 & 0.10 \\
\hline \multirow{3}{*}{$\Delta$ DollarFlow $(\mathrm{t}-1)$} & \multicolumn{6}{|c|}{ Panel C: Outflow } \\
\hline & 0.111 & 0.130 & 0.066 & 0.092 & $0.133^{* *}$ & 0.076 \\
\hline & {$[0.22]$} & {$[1.60]$} & [0.95] & {$[1.60]$} & {$[2.16]$} & [0.98] \\
\hline Controls & yes & yes & yes & yes & yes & yes \\
\hline Adj. R-sqr & 0.09 & 0.16 & 0.18 & 0.15 & 0.18 & 0.04 \\
\hline
\end{tabular}




\section{Table 11: TIPS-Treasury Spread}

The table reports the estimation results of the regression for the changes in the spread between STRIPS plus TIPS and Treasury yields with fixed maturity. 5- and 10-year tenors are used. The control variables are those used in Table 6 as well as those described in sub-section 3.6. DollarFlow is hedge fund flow scaled by the U.S. GDP as of the end of the previous year. "Total flow" indicates that total net dollar flow is used, "Inflow" and "Outflow" indicate the use of inflow and outflow respectively. $\Delta$ indicates monthly changes in the corresponding variable. NeweyWest t-statistics are reported in brackets. $* * *, * * *$ indicate significance at the 10 , 5 , and $1 \%$ level, respectively.

\begin{tabular}{|c|c|c|c|c|}
\hline & $5-y$ & ear & & year \\
\hline & & Panel A: T & tal flow & \\
\hline Const & $-0.001^{* *}$ & -0.000 & -0.000 & 0.000 \\
\hline & {$[-2.26]$} & {$[-0.22]$} & {$[-0.61]$} & {$[0.51]$} \\
\hline Crisis Dummy & & -0.000 & & 0.001 \\
\hline & & {$[-0.35]$} & & {$[1.23]$} \\
\hline Lag 1 & & 0.006 & & -0.069 \\
\hline & & {$[0.10]$} & & {$[-0.86]$} \\
\hline$\Delta \mathrm{VIX}$ & & -0.000 & & -0.000 \\
\hline & & {$[-0.86]$} & & {$[-0.01]$} \\
\hline$\Delta$ Noise & & $8.182^{* * *}$ & & $4.142^{* * *}$ \\
\hline & & {$[2.87]$} & & {$[2.85]$} \\
\hline MFExRet (t-1) & & -0.002 & & -0.013 \\
\hline & & {$[-0.09]$} & & {$[-0.52]$} \\
\hline MFFlow (t-1) & & $-0.020^{*}$ & & -0.019 \\
\hline & & {$[-1.68]$} & & {$[-0.88]$} \\
\hline HFExRet (t-1) & & -0.000 & & $0.032^{*}$ \\
\hline & & {$[-0.00]$} & & {$[1.81]$} \\
\hline Treasury Outstanding & -0.003 & -0.004 & -0.003 & -0.005 \\
\hline & {$[-0.79]$} & {$[-0.66]$} & {$[-0.85]$} & {$[-1.34]$} \\
\hline TIPS Outstanding & $0.087 * * *$ & $0.081^{* * *}$ & 0.031 & $0.034^{*}$ \\
\hline & {$[3.37]$} & {$[3.22]$} & {$[1.50]$} & {$[1.97]$} \\
\hline TIP/Treasury Trading & -0.045 & -0.032 & 0.038 & 0.029 \\
\hline & {$[-1.03]$} & {$[-0.69]$} & {$[0.97]$} & {$[0.75]$} \\
\hline Swap Spread & 0.544 & 0.564 & -0.740 & $-1.056^{* *}$ \\
\hline & [1.61] & {$[1.59]$} & {$[-1.31]$} & {$[-2.49]$} \\
\hline$\Delta$ DollarFlow $(\mathrm{t}-1)$ & $-0.224^{*}$ & -0.212 & -0.182 & $-0.453^{* *}$ \\
\hline & {$[-1.88]$} & {$[-1.45]$} & {$[-1.55]$} & {$[-2.42]$} \\
\hline R-sqr & 0.11 & 0.21 & 0.11 & 0.26 \\
\hline Adj. R-sqr & 0.09 & 0.15 & 0.07 & 0.16 \\
\hline $\mathrm{N}$ & 179 & 179 & 104 & 104 \\
\hline & & Panel B: & Inflow & \\
\hline$\Delta$ DollarFlow $(\mathrm{t}-1)$ & $-0.318^{*}$ & -0.241 & -0.165 & $-0.704^{* *}$ \\
\hline & {$[-1.82]$} & {$[-0.96]$} & {$[-0.93]$} & {$[-2.42]$} \\
\hline Controls & yes & yes & yes & yes \\
\hline Adj. R-sqr & 0.08 & 0.14 & 0.05 & 0.13 \\
\hline & & Panel C: & Jutflow & \\
\hline$\Delta$ DollarFlow $(\mathrm{t}-1)$ & 0.330 & 0.282 & 0.374 & $0.590^{* *}$ \\
\hline & {$[1.53]$} & {$[1.50]$} & {$[1.53]$} & {$[2.02]$} \\
\hline Controls & yes & yes & yes & yes \\
\hline Adj. R-sqr & 0.09 & 0.15 & 0.08 & 0.14 \\
\hline
\end{tabular}

